\title{
IUCN
}

Стратегии эффективного планирования в целях управления экологическим риском, связанным с геофизическими и иными исследованиями, направленными на получение графических изображений

Справочное руководство для менеджеров

Даглас П. Новачек, Брэндон Л. Саутхол

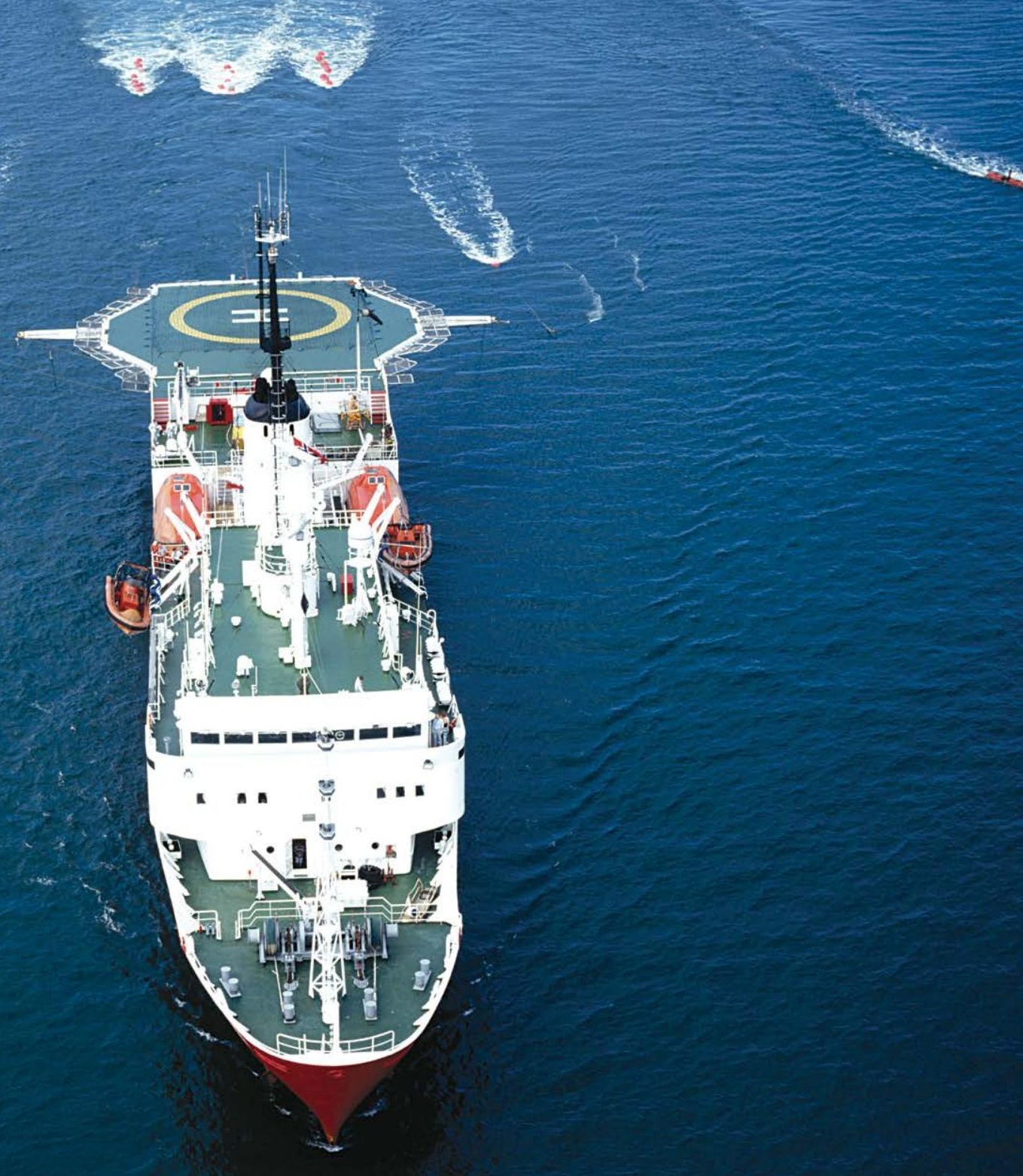




\section{O MCOח}

МСОП (Международный союз охраны природы) - уникальный по своему составу Союз, членами которого являются как правительственные, так и общественные организации. МсоП предоставляет государственным, частным и неправительственным организациямзнанияиподходы, обеспечивающие, чтобы развитиечеловечества, экономический прогресс и охрана природы происходили одновременно.

Основанный в 1948 году, МСОП в настоящее время является самой крупной и разветвленной в мире природоохранной организацией, которая объединяет знания, ресурсы и возможности 1300 организаций-членов Союза и около 15 тысяч специалистов. Союз является ведущим распространителем информации по охране природы, экспертным оценкам и аналитическим наработкам. Разнообразный состав членов дает возможность МСОП выполнять функцию разработчика и надежного хранилища наилучших практик, подходов и международных стандартов.

МСОП предоставляет назависимый форум, в рамках которого различные заинтересованные стороны, включая правительства, неправительственные организации, ученых, коммерческие компании, местные общины, организации коренных народов и другие объединения, могут совместными усилиями вырабатывать и реализовывать решения в области охраны окружающей среды, а также добиваться устойчивого развития.

На основе взаимодействия со множеством партнеров и содействующих организаций, МСОП управляет работой в рамках большого количества разнообразных проектов по охране природы во всем мире. Сочетая новейшие научные достижения с традиционными знаниями местных сообществ, такие проекты направлены на возвращение утраченных местообитаний, восстановление экосистем и улучшение качества жизни людей.

\section{www.iucn.org}

\section{twitter.com/IUCN/}




\section{Стратегии эффективного планирования в целях управления экологическим риском, связанным с геофизическими и иными исследованиями, направленными на получение графических изображений \\ Справочное руководство для менеджеров \\ Даглас П. Новачек ${ }^{1,2,5}$, Брэндон Л. Саутхол 13,4}

1 Кафедра наук о море и сохранении морских животных, Институт экологии им. Николаса, Морская лаборатория Университета Дьюка, Бофорт, Северная Каролина, США

2 Факультет компьютерной и электротехники, Инженерный институт им. Пратта, Университет Дьюка

3 Экологическая ассоциация Саутхолла, Аптос, Калифорния, США

4 Университет Калифорнии в Г.Санта-Круз, Санта-Круз, Калифорния, США

5 Комиссия МСОП по выживанию видов, Группа специалистов по китообразным 
Используемые термины и географические определения, упомянутые в настоящей публикации, и форма подачи соответствующей информации ни в коей мере не отражают мнения МсоП по поводу правового статуса той или иной страны, территории или региона, либо соответствующей администрации или делимитации государственных или административных границ.

Мнения, выраженные в данной публикации, могут не совпадать со мнениями Мсоп.

Перевод осуществлен при поддержке Проекта ПРООН/ГЭФ-Минприроды России «Задачи сохранения биоразнообразия в политике и программах развития энергетического сектора России»

МСОП и Проект ПРООН/ГЭФ - Минприроды России «Задачи сохранения биоразнообразия в политике и программах развития энергетического сектора России» не несут ответственности за возможные недостатки или ошибки в переводе данной публикации на русский язык (оригинал на английском языке)

Опубликовано:

МСоП, Гланд, Швейцария

Авторские права:

(c) 2017 Международный союз охраны природы и природных ресурсов (International Union for Conservation of Nature and Natural Resources)

Воспроизведение данной публикации в образовательных или иных некоммерческих целях разрешается без получения предварительного письменного разрешения правообладателя при условии полного признания источника публикации.

Воспроизведение данной публикации с целью перепродажи или в иных коммерческих целях запрещается без получения предварительного письменного разрешения правообладателя.

Наименование публикации для цитирования:

ISBN:

DOI:

Снимок на обложке:

Снимок на задней обложке:

Перевод на русский язык:

Исполнитель макета:

Издание доступно в:
Douglas P.Nowacek, Brandon L.Southall [Даглас П. Новачек, Брэндон Л. Саутхол] (2017).

стратегии эффективного планирования в челях управления экологическим риском, связанным с геофизическими и иными подобными исследованиями, направленными на получение графических изображений. Гланд, Швейцария: МСОП. [Trans. A. Danilov and A.Vladimirov. Effective planning strategies for managing environmental risk associated with geophysical and other imaging surveys. (IUCN, 2016).]

$$
\text { 978-2-8317-1858-3 }
$$

10.2305/IUCN.CH.2016.07.ru

(c) Джон Лоуренс Фотографи / Алами Сток Фото (John Lawrence Photography / Alamy Stock Photo)

(c) Бо Пардау (Bo Pardau)

Александр Данилов \& Алексей Владимиров

Юнит Графикс / Имре Себестьен Мл. (Unit Graphics / Imre Sebestyén Jr.)

МСОП (Международный союз охраны природы)

Глобальная программа по бизнесу и биоразнообразию

Рю Моверни, д.28

1196 г. Гланд

Швейцария

Тел. +41 229990000

Факс +41229990002

biobiz@iucn.org

www.iucn.org/resources/publications

В работе над окончательным и дополненным вариантом данного документа принимали значительное участие множество лиц и организаций. Мы выражаем благодарность Международной ассоциации производителей нефти и газа (МПНГ), Роберто Ракка из компании «АSCO Аррlied Sciences», а также трем анонимным рецензентам. Мы также хотим поблагодарить членов Консультативной группы по западнотихоокеанским серым китам под эгидой МСОП и сотрудников «Сахалин Энерджи» за их вклад в эту публикацию. Мы также благодарим за содействие Джулию Карбоне и Анете Берзину из МСОП, а также Элеанору Хейвуд, научную сотрудницу Университета Дьюка. В заключение, мы хотели бы отметить содействие со стороны компании «Сахалин Энерджи» и поблагодарить ее за финансовую поддержку. 


\section{Содержание}

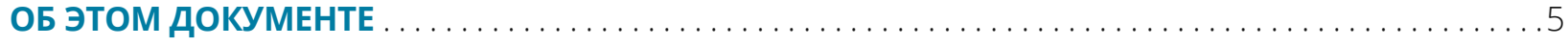

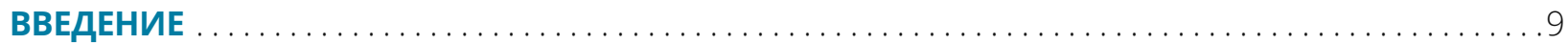

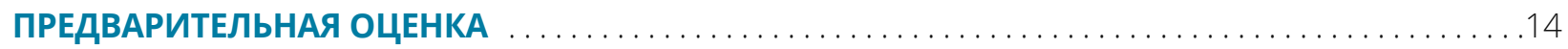

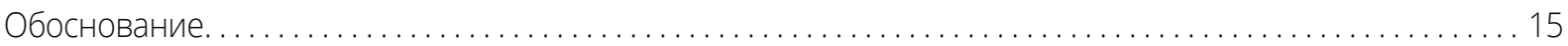

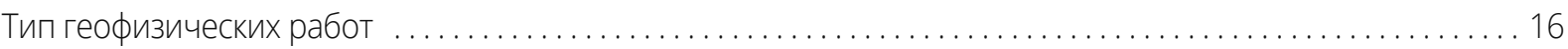

Физические особенности и хозяйственная деятельность в районе работ . . . . . . . . . . . . . . . . . 16

Виды, подвергающиеся потенциальному воздействию . . . . . . . . . . . . . . . . . . . . . . 17

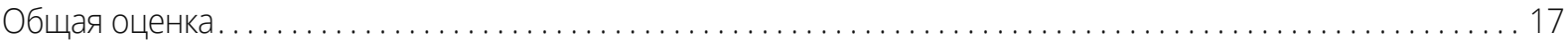

ЭТАП №1:

ОЦЕНКА ВОЗДЕЙСТВИЯ НА ОКРУЖАЮЩУЮ СРЕДУ

В КОНТЕКСТЕ НАМЕЧАЕМОЙ ДЕЯТЕЛЬНОСТИ. . . . . . . . . . . . . . . . . . . . . . . . . . . . 19

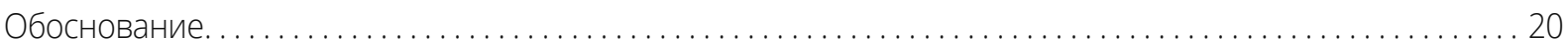

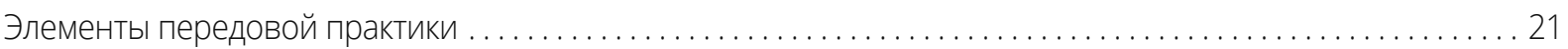

А. Сбор исходных экологических и биологических данных - биотические и абиотические компоненты

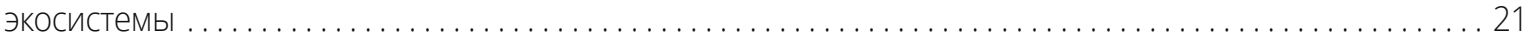

Б. Анализ воздействий и рассмотрение альтернатив (необходимо описать все этапы и осуществимые альтернативные стратегии вне зависимости от экономической целесообразности) . . . . . . . . . . . . . 22

С. Вовлечение заинтересованных сторон. . . . . . . . . . . . . . . . . . . . . . . . . . . . . . . . . 24

ЭТАП №2:

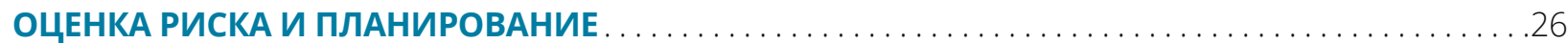

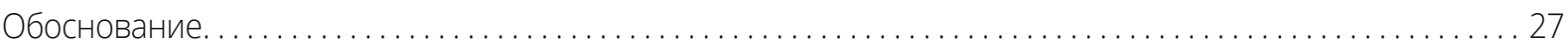

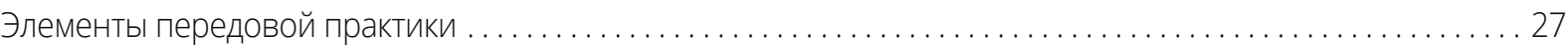

А. Оценка рисков, связанных с намечаемыми работами, и рассмотрение альтернатив . . . . . . . . . . . 27

Б. Идентификация мер по снижению воздействий . . . . . . . . . . . . . . . . . . . . . .... 30

С. Разработка стратегии и методов мониторинга для применения до, во время и после работ . . . . . 31

ЭТАП №3:

ОСУЩЕСТВЛЕНИЕ МЕР ПО СНИЖЕНИЮ ВОЗДЕЙСТВИЯ И ПРОВЕДЕНИЕ

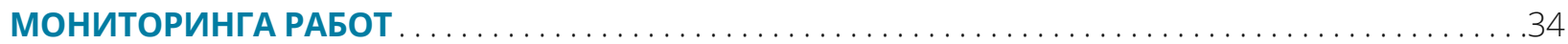

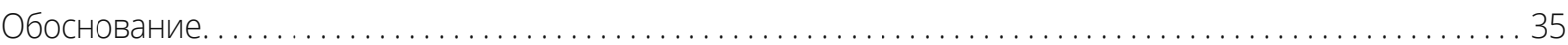

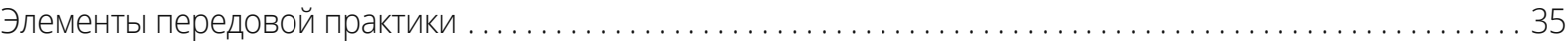

А. Применение мер по снижению воздействия в ходе выполнения работ . . . . . . . . . . . . . . . . . . 35

В. Применение мер по снижению воздействия в реальном времени . . . . . . . . . . . . . . . . . . 36

ЭТАП №4:

С. Осуществление протоколов мониторинга, включая проверку и хранение данных . . . . . . . . . . . . 37

ОЦЕНКА РЕЗУЛЬТАТОВ И ВНЕДРЕНИЕ УЛУЧШЕНИЙ $\ldots \ldots \ldots \ldots \ldots \ldots \ldots \ldots \ldots \ldots \ldots \ldots \ldots \ldots \ldots$

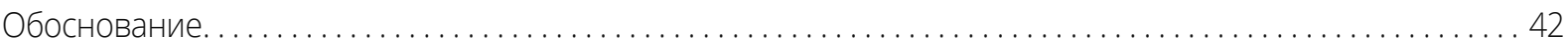

Элементы передовой практики ........................................... 43

А. Отчетность об эффективности программы по снижению воздействия. ....................43

В. Рассмотрение результативности программы мониторинга . ........................ 43

С. Своевременный анализ данных и обеспечение доступности результатов . . . . . . . . . . . . . . . . . . 44

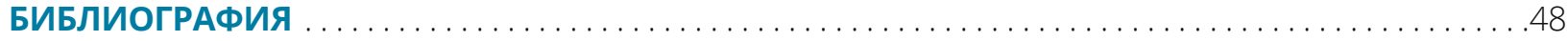

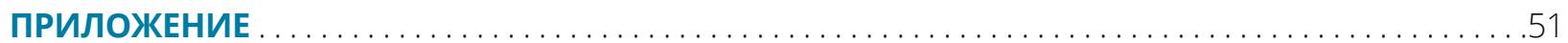

Стратегии эффективного планирования в целях управления экологическим риском, связанным с геофизическими и иными исследованиями, направленными на получение графических изображений 



\section{Об этом документе}

Данный документ является практическим руководством по ответственному и эффективному планированию морских геофизических исследований и иных исследований, направленных на получение графических изображений окружающей среды. Документ призван способствовать как улучшению понимания воздействий, которые такие исследования оказывают на природные компоненты, так и улучшению планирования последующих мероприятий.

С целью повышения согласованности как в оценках, так и в снижении уровня потенциальных воздействий, процесс, описанный в данном документе, включает систематическую оценку различных видов деятельности и потенциальных воздействий, с учетом того, что таковые могут приводить к нарушению законов сразу нескольких административно-территориальных единиц. Основное внимание уделяется морским млекопитающим, на которых, несмотря на их статус хищников высшего порядка в большинстве морских экосистем, распространяется существенная нормативно-правовая защита в многих странах мира. Тем не менее, элементы данного инструмента планирования применимы и могут быть адаптированы для применения в отношении видов, имеющих важность на локальном уровне, таких как рыбы, морские черепахи, морские птицы.

Целевая аудитория включает отраслевые предприятия (как менеджеров по охране окружающей среды, так и руководителей различных исследований), надзорные органы (сотрудников органов государственной власти, отвечающих за проведение оценки планов предприятий на предмет наличия эффективных мер снижении потенциальныхнегативныхвоздействийна окружающуюсреду), атакжеученых (которыемогут консультировать отраслевые предприятия, органы государственной власти и иных заинтересованных субъектов).

Ожидается, что это будет «живой документ», основанный на отзывах и предложениях, а также обновлениях к руководствам и нормативным положениям в разных странах мира; настоящая редакция документа была составлена на основе доступных публикаций (см. Приложение), а также благодаря прямым консультациям с отраслевымипредприятиями, органамигосударственнойвластииприродоохранными неправительственными организациями и с учетом их отзывов. Документ будет обновляться в рамках непрерывного диалога и взаимодействия с различными заинтересованными сторонами, включая МСОП, отраслевые предприятия, органы государственной власти и прочие организации

Стратегии эффективного планирования в целях управления экологическим риском, связанным с геофизическими и иными исследованиями, направленными на получение графических изображений 


\section{КРАТКАЯ АННОТАЦИЯ}

Настоящийдокументпредставляет собойпрактическое руководство по ответственному иэффективномупланированию морских геофизических исследований и иных исследований, направленных на получение графических изображений окружающей среды. В нем описывается механизм структурированной, систематической экспертизы и принятия решений для хозяйствующих субъектов, органов государственной власти и ученых. Основные элементы, структура и последовательность действий в этом механизме позаимствованы из работы Д.Новачека и соавторов, опубликованной в 2013 г.. Хотя основное внимание в этом документе уделяется морским млекопитающим, предлагаемый подход может применяться в любой ситуации, которая затрагивает охраняемые и уязвимые виды (ОУВ).

Подход, представленный в настоящем документе, начинается с предварительной оценки имеющейся информации о характере намечаемой деятельности и особенностях окружающей среды в соответствующем районе, затем представлен рядпрактикпланирования, выполнения и оценки мероприятий по снижению воздействия и мониторингу.

\section{Предварительная оценка}

Прежде чем начинать какие-либо работы, потребуется провести первичную комплексную оценку риска в отношении общего характера намечаемых геофизических работ и компонентов окружающей среды в районе работ, чтобы оценить масштаб и степень проработки необходимых мероприятий. При этом потребуется оценить тип, масштаб, продолжительность и параметры намечаемой деятельности, а также характеристики окружающей среды и виды животных, которые могут подвергнуться воздействию в районе работ.

\section{Этап №1. Оценка воздействия на окружающую среду в контексте намечаемой деятельности}

Следующим этапом после выполнения предварительной оценки является должным образом проведенная оценка воздействия на окружающую среду намечаемой деятельности. Для этого может потребоваться изучение имеющихся данных, если данный район хорошо изучен, или дополнительный сбор исходных экологических данных, если район изучен относительно слабо. Этот этап состоит из соедующих элементов:

\section{- сбор исходных экологических и биологических данных (биотические и абиотические характеристики} экосистемы), включая обзор и оценку данных за ряд предыдущих лет об охраняемых и уязвимых видах, а также иных видах, которые могут подвергнуться воздействию, данных о характеристиках экосистемы и физических аспектах окружающей среды;

- анализ планируемых и альтернативных вариантов, включая параметры мощности излучения сейсмических источников, используемое оборудование, алгоритмы и допущения для моделирования распространения звука и звукового воздействия, а также альтернативные подходы и методы, которые могут уменьшить общее звуковое воздействие на ОУВ; и

вовлечение заинтересованных сторон, включая информирование общественности, консультации и взаимодействие с физическими лицами, неправительственными организациями или органами государственной власти, которых может интересовать или на деятельность которых может влиять намечаемая деятельность.

Стратегии эффективного планирования в целях управления экологическим риском, связанным с геофизическими и иными исследованиями, направленными на получение графических изображений 


\section{Этап №2. Оценка риска и планирование}

После завершения описанной на этапе №1 экспертизы намечаемой деятельности и оценки воздействия на окружающую среду, следующим этапом является проведение структурированного анализа рисков с целью определения интенсивности воздействий, которые могут быть вызваны намечаемой деятельностью. Этот этап содержит следующие элементы:

- оценка рисков, связанных с намечаемой деятельностью и альтернативами, на основе параметров намечаемой деятельности и экологических и биологических характеристик. В рамках этой оценки должен быть проведен анализ звукового воздействия, анализ потенциальных временных и постоянных эффектов и оценка прогнозных показателей вероятности возникновения ответных реакций у подвергающихся воздействию видов;

- идентификация мер по снижению воздействия, включая конкретные цели снижения воздействия, протоколы обнаружения ОУВ и подготовку и координацию действий соответствующих групп сотрудников; и

- разработка стратегии и методов мониторинга для применения до, во время и после работ. Следует разработать протоколы для мониторинга всех ОУВ и интегрировать их в осуществляемые в реальном времени меры по снижению воздействия. Кроме того, должен быть предусмотрен план комплексной отчетности.

\section{Этап №3. Осуществление мер по снижению воздействия и проведение мониторинга работ}

На данном этапе должен быть выполнен план по снижению воздействия и мониторинга, разработанный в рамках Этапа №2. Этот этап содержит следующие элементы:

- осуществление мер по снижению воздействия в ходе работ сучетом сроков их проведения ихарактеристик источника воздействия;

- осуществление мер по снижению воздействия в реальном времени, включая официальные протоколы и целенаправленные меры, осуществляемые должным образом подготовленным персоналом; и

- выполнение протоколов мониторинга, включая проверку и надлежащее хранение данных, В целях обеспечения результативной отчетности и дальнейшего анализа данных по окончании работ.

\section{Этап №4: Оценка результатов и внедрение улучшений}

Оценка результатов и внедрение улучшений должны начинаться после завершения работ, при этом необходимо осуществить две взаимосвязанных задачи: представить тщательный анализ результативности выполнения плана мониторинга и мер по снижению воздействия и выявить полезные уроки, которые следует учесть в последующих программах мониторинга и снижения воздействия. Важно, чтобы материалы наблюдений и результаты аналитических работ были раскрыты настолько, насколько это возможно, всем заинтересованным субъектам и сторонам. Этот этап содержит следующие элементы:

- отчетность о результативности программы снижения воздействия, включая обзор работ, трудозатрат, эффективности выполнения мер по снижению воздействия, значимых событий, анализ первичных данных и краткосрочные и среднесрочные планы по их дальнейшему анализу;

- обзор результативности программы мониторинга с целью последующего улучшения мер по снижению воздействия; и

- надлежащий анализ и обеспечение доступности результатов в целях информационного обеспечения последующих оценок риска и разработки мероприятий по снижению воздействия и мониторингу, а также выявления и ликвидации пробелов в данных для обеспечения эффективного проведения последующих работ и исследований состояния экосистем.

Стратегии эффективного планирования в целях управления экологическим риском, связанным с геофизическими и иными исследованиями, направленными на получение графических изображений 



\section{Введение}

Настоящий документ представляет собой практическое руководство по ответственному и эффективному планированию морских геофизических исследований и иных исследований, направленных на получение графических изображений компонентов окружающей среды, в особенности в том, что касается морских млекопитающих, хотя соответствующие принципы и методы могут быть применимы в отношении любых охраняемых и уязвимых видов (ОУВ, как их определяют МСОП и (или) местные или национальные органы государственной власти). Основное внимание (в том числе в соответствующих примерах) уделяется планированию и проведению крупномасштабных геофизических работ с использованием пневматических источников, принимая во внимания относительную интенсивность инизкую частоту источников, используемых по всему миру. Кроме того, здесь рассматривается ответственное планирование других видов исследований в целях получения графических изображений компонентов окружающей среды (например с использованием определенных типов систем с многолучевыми гидролокаторами), которые часто применяются для разведки и добычи энергоносителей или картирования морского дна. В настоящем документе предлагается структурированная основа для анализа и принятия решений, призванная дополнить другие существующие рекомендации по наилучшим практикам в области охраны окружающей среды, разработанные отраслевыми предприятиями и иными субъектами (такими как Международная ассоциация геофизических подрядчиков (IAGS), Международная ассоциация представителей нефтяной промышленности по охране окружающей среды и социальным вопросам (IPIECA), Объединенный комитет охраны природы (INCC). Документ призван принести дополнительную пользу в связи с тем, что он был в значительной мере разработан учеными, знакомыми со многими проблемами в области охраны окружающей среды и биологии, которые имеют ключевое значение для мониторинга и снижения воздействия.

В рамках экологически ответственного подхода при проведении геофизических работ необходимо должным образом учитывать то обстоятельство, что коммерческие, социальные и экологические интересы могут противоречить друг другу. Ответственныекомпаниибудутвыполнятьнеобходимыеоценкирискассоблюдением принципов открытости и прозрачности, чтобы убедиться в наличии должного баланса между риском воздействия на местообитания и интересами широкого круга заинтересованных сторон. Общие принципы и рекомендации представлены здесь с целью содействия в проведении последовательного, результативного и эффективного планирования, проведения и оценки работ в том, что касается потенциального воздействия на окружающую среду. Все этапы работы (до, во время и после) анализируются в рамках итеративного процесса на основе оценки риска. Рекомендации основаны на значительном прогрессе, достигнутом благодаря научным исследованиям и прямым наблюдениям за промышленными работами и связанным с ними мониторингом и мерами по снижению воздействия геофизических и иных промышленных работ, которые выполнялись на протяжении ряда лет. Повышение требований в отношении экспертизы намечаемой деятельности со стороны надзорных органов, устойчивая положительная динамика исследовательскихусилий (включая новые тренды в оценке биологической значимости беспокоящего воздействия и потенциально взаимосвязанных или хронических видов воздействий), а также достижения технического прогресса являются основой для реализации разумного и структурированного подхода к ответственному проведению морских геофизических исследований с высокой разрешающей способностью и иных видов графического отображения данных.

Концептуальной основой для настоящего руководства служит публикация Новачека и соавторов (2013 г.), описавших элементы ответственного проведения геофизических работ с акцентом на экологически уязвимые районы. Как подчеркивается в упомянутой публикации, не все отдельные элементы основных этапов, указанных ниже, будут обязательно применимы к каждому типу работ. В настоящем документе приводится описание модельной ситуации, при которой необходимо значительное предварительное планирование для

Стратегии эффективного планирования в целях управления экологическим риском, связанным с геофизическими и иными исследованиями, направленными на получение графических изображений 
проведения экологических исследований еще до начала оценки риска и процедуры получения разрешений. Несмотря на то, что такая ситуация не всегда может быть возможной илиже не требуется в рамках действующих правовых норм в части охраны окружающей среды, в качестве некоего эталона предлагается модельный вариант и предусматривается подход, основанный на принципе предосторожности в отношении научной недостоверности имеющихся данных в рамках любой оценки риска.

Очевидно, что выполнение данных принципов на практике будет зависеть от специфики ситуации, и следует учитывать множество экологических, производственных и нормативных контекстов, в которых по всему миру проводятся геофизические и иные исследования с целью получения графических изображений, в связи с чем будет варьироваться уровень оцениваемого риска. Несмотря на это, необходимость адаптации к конкретным локальным сценариям и действующим нормативно-правовым требованиям не означает, что утрачивает силу логический подход при планировании, оценке риска, реализации и последующем анализе с целью ответственного проведения намечаемых работ и информационного обеспечения последующих работ, подобных описанным здесь. В настоящем документе предлагается итеративный анализ, основанный на оценке риска, начиная с предварительной проверки ключевых факторов, касающихся источников звука, морских млекопитающих и окружающей среды в относительно широком контексте, а затем предлагается ряд методов, связанных с планированием, проведением работ и анализом.

Базовые элементы, организация и рекомендуемая последовательность методов, описанных здесь, были заимствованы из работы Новачека и соавторов (2013 г.) и представлены на Рис. 1 и уточнены на Рис. 2. Цель заключается в том, чтобы в настоящей работе представить подробную информацию о последовательности процессов, а также актуальные и исчерпывающие ссылки на принятую в определенных регионах практику проведения работ, нормативно-правовые требования и критерии, анализ и способы хранения данных, а также иные практические указания в отношении планирования. Приложение (которое находится на веб-сайте МСОП и будет регулярно обновляться) представляет собой вспомогательный ресурс для более детального дополнения к некоторым вопросам, которые следует учитывать при составлении плана геофизических исследований. В Приложении указаны релевантные документы из базы данных о публикациях; помимо основных научных публикаций, в Приложении перечислены нормативно-правовые документы и регламенты, которые могут быть полезны для операторов и менеджеров.

Приветствуется использование инструментов для оценки и планирования, которые имеются в распоряжении менеджеров; представлены соответствующие примеры. За последнее десятилетие существенно усовершенствовались доступные инструменты для мониторинга как нормального поведения, так и для оценки воздействия и реакций животных в районе проведения геофизических работ (например пассивные акустические измерения, моделирование распространения звука, способы отслеживания судов). Аналогичным образом, произошел существенный прогресс в развитии методов выборки и анализа информации о поведении животных (например, интегрирование выборки по акустике и визуальным наблюдениям, удаленное отслеживание с помощью меток). Наконец, аналитические инструменты для оценки воздействий (например, суммарного шумового воздействия), включая кумулятивное воздействие, становятся все более надежными и доступными. Несмотря на многие сохраняющиеся сложности (например, до сих пор не сформулировано широко признанное и согласованное определение «незначительного воздействия» шума), уже опубликованы аналитические платформы (например в работах Фляйшмана и соавторов, 2016 г.), что позволяет включить в них результаты программ по мониторингу и снижению воздействия, подобных тем, что описаны в настоящем документе.

Оценка риска является общепринятой практикой для самых разных предприятий энергетического сектора. Описанный в настоящем документе подход к оценке риска для окружающей среды является всего лишь одним из таких методов. Несмотря на то, что подобные процедуры уже применяются некоторыми промышленными операторами в той или иной степени (например, МАПНГ и МАГП, 2011 г., см. Приложение), цель данного

Стратегии эффективного планирования в целях управления экологическим риском, связанным с геофизическими и иными исследованиями, направленными на получение графических изображений 
документа - рекомендовать структурный и последовательный, и, в то же время, адаптивный метод, учитывающий особенности в сфере биологии, и который может широко применяться. В рамках такой оценки риска для окружающей среды анализируются, среди прочих, следующие вопросы: Присутствие каких животных ожидается в месте проведения работ? Каков(-ы) источник(-и) пищи таких животных? и Каким образом можно снизить степень потенциального воздействия?

В настоящем документе показана необходимость и эффективность комплексной оценки риска, выполнения пересмотра программы экологического мониторинга с учетом того, что проекты, направленные на получение графической информации о компонентах окружающей среды являются разноплановыми, где экологические аспекты являются только одним из элементов проекта в целом. Успех компании, как правило, измеряется по ее финансовым показателям. С точки зрения акционеров компании, ответственное планирование мер по охране окружающей среды логично с точки зрения бизнеса. Компании, ведущие ответственную политику в отношении охраны окружающей среды, более конкурентоспособны, их деятельность сопряжена с меньшими рисками и общественность, надзорные органы и другие заинтересованные стороны относится к ним более благосклонно. Поскольку каждый проект, связанный с получением графических изображений различных компонентов окружающей среды, уникален, настоящее руководство не включает расчет возможных издержек, связанных с ответственным экологическим планированием. Тем не менее, руководство призывает к планированию геофизических исследований эффективным и ответственным образом, что должно сочитаться по важности с другими элементами проекта, в особенности, с теми, которым зачастую уделяется недостаточно внимания (т.е., анализу результатов мониторинга и снижения воздействия). Интеграция экологически ответственного планирования в процесс планирования проекта в долгосрочной перспективе принесет значительную пользу как хозяйствующим субъектам, так и окружающей среде. 


\section{ОБЩЕЕ ПМАНИРОВАНИЕ ПРОГРАММЫ И ОЦЕНКА РИСКА

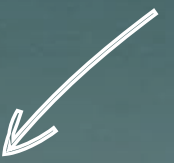

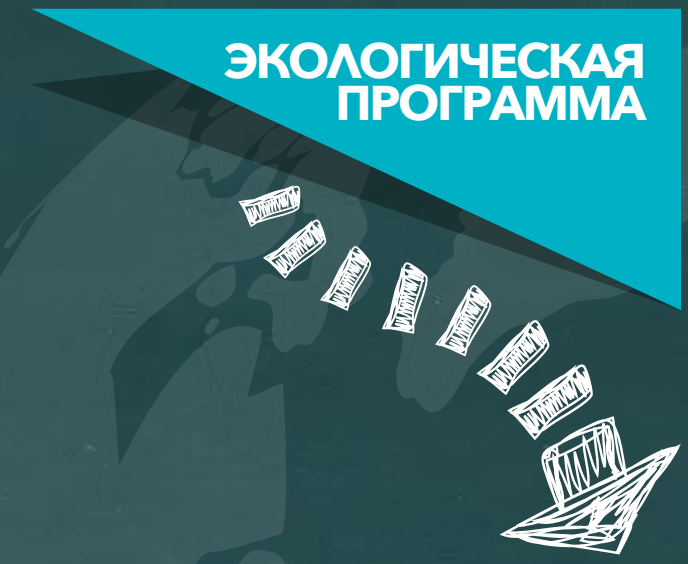

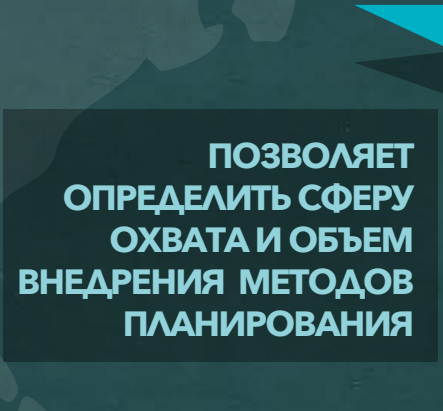

Pис. 1.

Концептуальная схема, в которой показаны методы, из которых состоит настоящее РУковОАСТВо, и которая показывает, как они вписываются в более масштабные программы планирования и оценки, осуществляемые компаниями в ходе процесса в целом. 4 центральных этапа представлены на Рис. 2 и в тексте.

\section{ПРЕАВАРИТЕАЬНАЯ} ПPOBEPKA
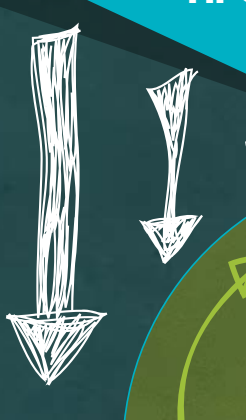

METOAb ИТЕРАТИВНОГО ЭКОАОГИЧЕСКОГО ПМАНИРОВАНИЯ

(РИС. 2)
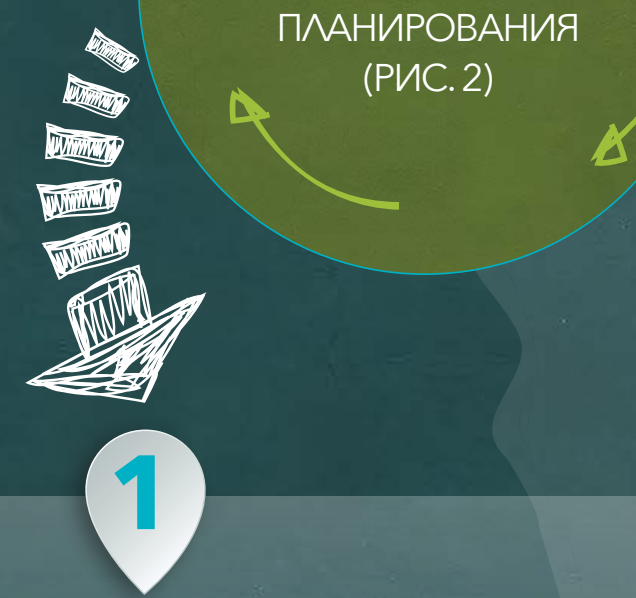

ЗКСПЕРТИЗА ӘКОАОГИЧЕСКОЙ ПРОГРАММЫ

\section{ПРОЧИЕ ПРОГРАММЬ} ПМАНИРОВАНИЯ PADOT

АНАМИЗ ЭФФЕКТИВНОСТИ ЗАТРАТ

口 АОГИСТИКА ПОАЕВЫХ РАБОТ

口 ОТПБ

口 КОНТРОАЬ КАЧЕСТВА И ОТЧЕТНОСТЬ

而

Liin

iin

(1)inini

(iiiniin

METOAb

ПАРАМЕАЬНОГО

(1)iini.

ПИАНИРОВАНИЯ,

ВЫПОАНЕНИЯ И

ЭКСПЕРТИЗЫ

\section{ЭКСПЕРТИЗА И ОЦЕНКА ВСЕИ ПРОГРАММЫ}




\section{ЭАЕМЕНТЫ ПЕРЕАОВОЙ ПРАКТИКИ НА ЭТАПАХ ЭФФЕКТИВНОГО ПМАНИРОВАНИЯ}

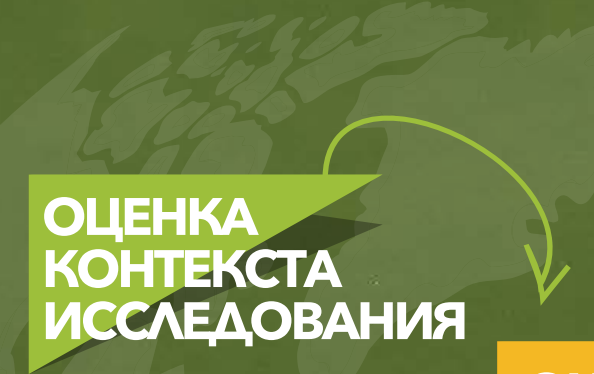

\section{1 БАЗОВЫЕ $\triangle$ AHНЫЕ}

2. АЕЙСТВИЯ И

2 AЛЬTEРНАТИВНЫЕ ПАРAMETPЫ
3 ВЗАИМОАЕЙСТВИЕ ССУБЪЕКТАМИ

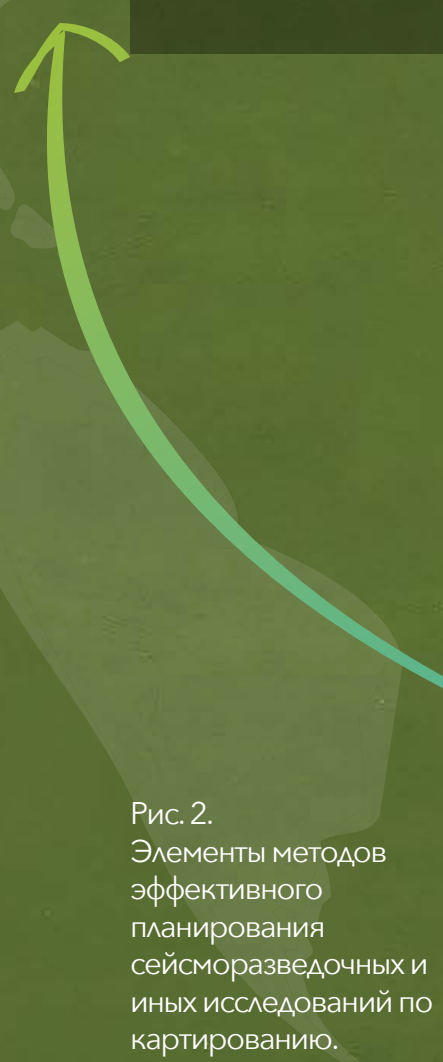

\section{OLIEHKA ИИСKA И РАВРАБОТKA TAAHOB}

1 ОЦЕНКА РИСКА

2 РАЗРАБОТКА

2 ЭФФЕКТИВНЫХ МЕР СНИЖЕНИЯ ВОЗАЕЙСТВИЯ

2 РАЗРАБОТКА ЭФФЕКТИВНОГО МОНИТОРИНГА

\section{PEAM ИЗАLИЯ MEP CHИЖKЕНИЯ ВОЗАЕИСТВИЯ И МОНИТОРИНГА}

РЕАМИЗАЦИЯ

МЕР СНИЖЕНИЯ ВОЗАЕЙСТВИЯ

2) РЕАМИЗАЦИЯ

МОНИТОРИНГА

2. ПРОВЕРКА

$\triangle A H H Ы X И$ АРХИВИРОВАНИЕ
ЭКСПЕРТИЗАИ УАУบШЕНИЯ

ОЦЕНКА
ЭФФЕКТИВНОСТИ
МЕР СНИЖЕНИЯ
ВОЗАЕЙСТВИЯИ
МОНИТОРИНГА
ОПЕРАТИВНОЕ
РАСКРЫТИЕИ
ПУБАИКАЦИЯ
РЕЗУАЬТАТОВ
ИНФОРМАЦИОННОЕ
ОБЕСПЕЧЕНИЕ
ААМЬНИИШИ
РАБОТ




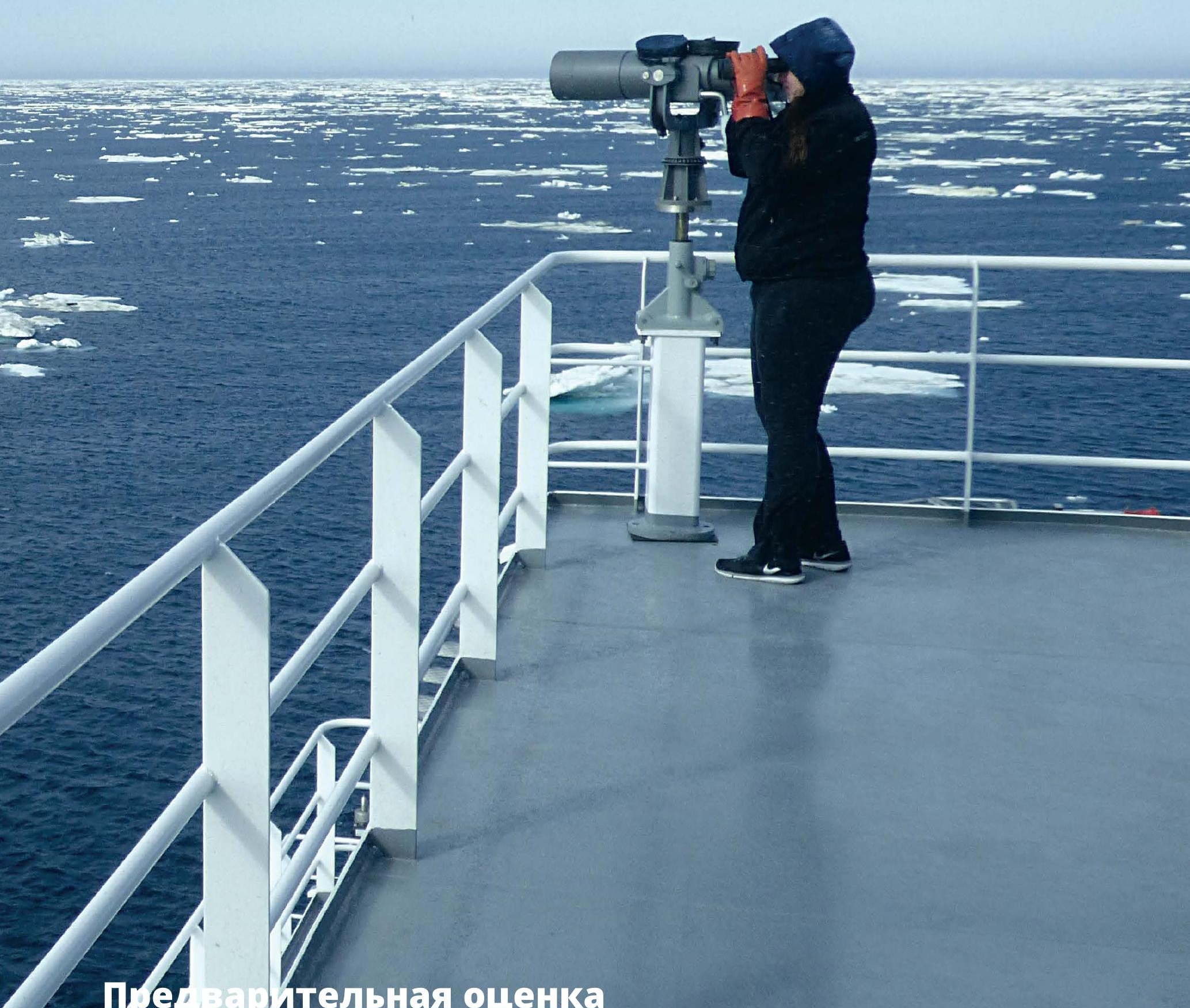




\section{Обоснование}

Итеративные методы для реализации стратегий эффективного планирования, описанные ниже, являются комплексными и охватывают полный диапазон возможных инструментов, которые могут использоваться и в некоторыхслучаяхдолжныприменятьсяв рамкахответственногопланированияиправовогопроведенияморских геофизических или иных видов исследований с целью получения графической информации о компонентах окружающей среды. Необходимо признать, что существует широкий спектр условий, от которых зависит, какие методы и с какой степенью детализации должны применяться. Кроме того, существует ряд видов деятельности, на которые может распространяться определение геофизических работ или морских геофизических исследований, направленных на получение графических изображений компонентов окружающей среды. Также существует множество условий, определяющих относительный уровень риска, и, следовательно, тип(-ы) мер по снижению воздействий и мониторинга, а также масштаб их применения. Дополнительные факторы, которые помогают определить подходящие типы и масштаб применения мер по снижению воздействий и мониторинга, включают тип и время проведения работ, условия окружающей среды, в которых они будут проводиться, иные виды деятельности в рассматриваемом районе, а также виды животных, которые потенциально могут подвергаться воздействию (см. Таблицу 1 с оценкой имеющихся исходных данных).

Таблица 1. Руководство для оценки типа и степени наличия исходной информации. Три категории необходимой исходной информации включают: наличие и распределение охраняемых и уязвимых видов (ОУВ), физические и биологические факторы окружающей среды, а также подверженность местности воздействию хозяйственной деятельности в настоящем и будущем. Предлагаются типы и источники таких данных, хотя список является далеко не исчерпывающим. Наконец, предлагается многоуровневая система со ссылками на конкретные примеры для того, чтобы специалисты, ответственные за планирование работ, смогли сформировать для себя представление об уровне достаточности исходных данных.

\section{Исходные данные - рекомендации по применению в рамках оценки}

\section{Элементы необходимой исходной информации и релевантные типы данных*:}

I. Наличие и распределение охраняемых и уязвимых видов (ОУВ)

- Визуальные наблюдения с воздуха/судна/берега

- Пассивный акустический мониторинг

II. Физические/биологические факторы окружающей среды

• Течения, ледовые условия, батиметрия, кормовые районы, погодные условия

III. Существующая и прогнозируемая хозяйственная деятельность (помимо геофизических съемок)

- Иная деятельность по разработке месторождений нефти и газа

- Судоходство, рыболовство, строительство, действия ВМС, акустические исследования

*Примечание: Источники данных могут включать существующую литературу, отчеты, анализы предыдущих отчетов или иную информацию, доступную из открытых источников.

\begin{tabular}{|c|c|c|c|}
\hline Исходные данные - & Уровень & Уровень 3 & Уровень 4 \\
\hline Данные отсутствуют & Данные за короткий & Многолетние данные & включают 1-2 набора \\
или в наличии имеются & период времени из 2 & данных (например, & Многолетние \\
крайне ограниченные & разноплановые данные \\
данные за короткий & или более источников & Ривз и др., 2014 г.); & (например, Мюир и др., \\
период времени & данных & дополнительные данные & 2016 г.) \\
\hline
\end{tabular}

Стратегии эффективного планирования в целях управления экологическим риском, связанным с геофизическими и иными исследованиями, направленными на получение графических изображений 
Рекомендуется проведение предварительной, общей оценки риска в связи с общей спецификой намечаемой деятельности и окружающей среды. Это важно для определения относительного объема и масштаба усилий, требуемых для выполнения этапов, описываемых ниже. Структура и реализация усилий в целом будут зависеть от вида деятельности, субъекта хозяйственной деятельности и нормативно-правовых требований.

\section{Тип геофизических работ}

Характер геофизических исследований, несомненно, является основным фактором в определении соответствующего потенциального риска для окружающей среды. Неполный список основных элементов приводится ниже:

- являются ли планируемые геофизические работы отдельным мероприятием или частью серии геофизических исследований или комплекса работ по освоению конкретного месторождения;

- географический масштаб;

- общая продолжительность работ, время года и график проведения работ;

- количество и типы (например пневмопушки, многолучевые гидролокаторы) источников звука, планируемые к применению - необходимо указать характеристики мощности различных источников;

- степень привлечения смежных вспомогательных морских и воздушных судов помимо носителей источников звука, которые имеют непосредственное отношение к намечаемым геофизическим работам;

- степень перекрытия участка проведения геофизических работ с районами, имеющими экономическую (например, для рыболовного промысла) или культурную значимость (например, места ведения натурального хозяйства или области, представляющей особый интерес).

Вероятно, что геофизические работы и сопутствующая деятельность будут сопряжены с более высоким потенциальным уровнем риска в следующих случаях:

- повторяющиеся геофизические работы или работы, относящиеся к крупномасштабной разработке месторождений (например, наличие различных операторов или месторождений) в пределах одной географической области;

- геофизические работы сосредоточены в ареалах уязвимых видов;

- такие работы носят непрерывный характер и (или) приходятся на периоды, важные с точки зрения биологии обитающих и встречающихся видов;

- есть вероятность, что в работах будут задействованы дополнительные интенсивные источники звука (например, гидролокаторы), воспринимаемые охраняемыми видами, в особенности при использовании множества таких источников;

- такие работы связаны с большим числом вспомогательных операций; и

- такие работы способны помешать иным видам хозяйственной деятельности, имеющей экономическую или культурную ценность.

\section{Физические особенности и хозяйственная деятельность в районе работ}

Подобным образом, особенности окружающей среды, при которыхпредполагается проведение геофизических работ, могут оказать серьезное влияние на сопутствующие потенциальные риски, а также на планы по мониторингу и снижению воздействия. Данные особенности включают (как минимум) следующее:

- случайный или постоянный характер проводимых на производственном участке геофизических работ;

- масштабы иных геологоразведочных операций или другой деятельности (например, рыболовства или судоходства) в районе проведения работ;

- проведение работ на мелководье или, наоборот, в глубоководных местах;

Стратегии эффективного планирования в целях управления экологическим риском, связанным с геофизическими и иными исследованиями, направленными на получение графических изображений 
- батиметрия и сложность рельефа дна;

- характеристики местообитаний, важные для потенциально уязвимых видов (например, распределение кормовых объектов); и

- климатические и погодные условия в течение временного промежутка фактического проведения геофизических работ.

Геофизические работы в районах, где редко проводятся инженерные и иные изыскания, могут быть связаны с более серьезным риском в виде резких, краткосрочных последствий (например, поведенческих реакций), чем изыскания, проводимые в регионах, где подобная деятельность является обычной. Несмотря на то, что геофизические работы, проводимые в районах, где осуществляется много иных работ, могут сопровождаться более низкими рисками в виде краткосрочного беспокоящего воздействия (например, животные могут демонстрировать некоторую устойчивость в отношении геофизических работ), такие работы могут повысить вероятность необратимых последствий. Геофизические работы на мелководье могут оказывать влияние на множество видов, однако работы, проводимые вблизи границ шельфа, подводных возвышений или других подводных объектов, включая те, вокруг которых формируются агломерации кормовых видов, могут сопровождаться более высокой степенью потенциального риска и требовать применения дополнительных мер снижения воздействия и мониторинга. Наконец, гидрологические условия (например, температура, батиметрия, состав субстрата) могут оказывать значительное влияние на распространение звука.

\section{Виды, подвергающиеся потенциальному воздействию}

Распределение и плотность видов, подвергающихся потенциальному воздействию, являются очень важными параметрами при оценке потенциального риска. Очевидно, что эти параметры сильно зависят не только от факторов окружающей среды, указанных выше, но и от различных элементов в привязке к конкретному виду, а именно:

- находится ли данный вид или популяция в уязвимом положении или в опасности;

- носит ли присутствие данного вида во время проведения геофизических работ постоянный характер, или район является транзитным для данного вида;

- будут ли геофизические работы приходиться на периоды, важные с точки зрения биологии обитающих и встречающихся видов, например, размножение или вскармливание; и

- особенности слуха и уязвимость конкретных видов в отношении звуковых источников, которые применяются при проведении геофизических работ.

Болеевысокийпотенциальный рисксточки зрения сохранения видов, вероятно, будет связансгеофизическими работами, проводимыми в местах обитания видов, находящихся подугрозой или на грани исчезновения. Более высокая степень риска может также иметь место в ситуациях, когда соответствующие виды встречаются в местахпроведения геофизических работ, по причине, имеющей биологическую природу (например, рождение детёнышей, спаривание), когда присутствуют животные, особенно уязвимые к беспокоящему воздействию, а также там, где встречаются виды, которые воспринимают и используют звуки на частотах, схожих с теми, которые используются в ходе геофизических работ.

\section{Общая оценка}

Процесс предварительной оценки, представленный здесь, основан на идеальныхусловиях, в которых имеется достаточно времени для предварительного планирования экологических изысканий и других исследований до начала оценки риска и процедуры получения разрешений. Более того, многие требования по охране окружающей среды, установленные органами исполнительной власти, предусматривают использование

Стратегии эффективного планирования в целях управления экологическим риском, связанным с геофизическими и иными исследованиями, направленными на получение графических изображений 
достоверных научных данных, а также выявление и устранение тем или иным способом существующих неопределенностей в документации для последующего принятия решений. Каждые геофизические исследования и условия, в которых они проводятся, обладают уникальными аспектами, в связи с чем было бы нереалистично ожидать, что можно было бы внедрить строго формализованный процесс оценки риска, в котором были бы учтены все вышеуказанные соображения при том, что все уникальные аспекты также были бы учтены.

Тем не менее, всегда желательно проводить предварительную оценку операционных, экологических и биологических факторов, указанных выше, в контексте текущей оценки воздействия на окружающую среду и процесса планирования. Масштаб и характер применения подходов (описанных ниже) будет зависеть от результатов данной оценки. В тех случаях, когда будут выявлены факторы, связанные с относительно высоким потенциальным риском, следует руководствоваться более комплексным подходом к применению описанных в настоящем документе подходов по охране окружающей среды, что может подразумевать учет сезонных или пространственных ограничений или изменений в плане проведения геофизических работ. 


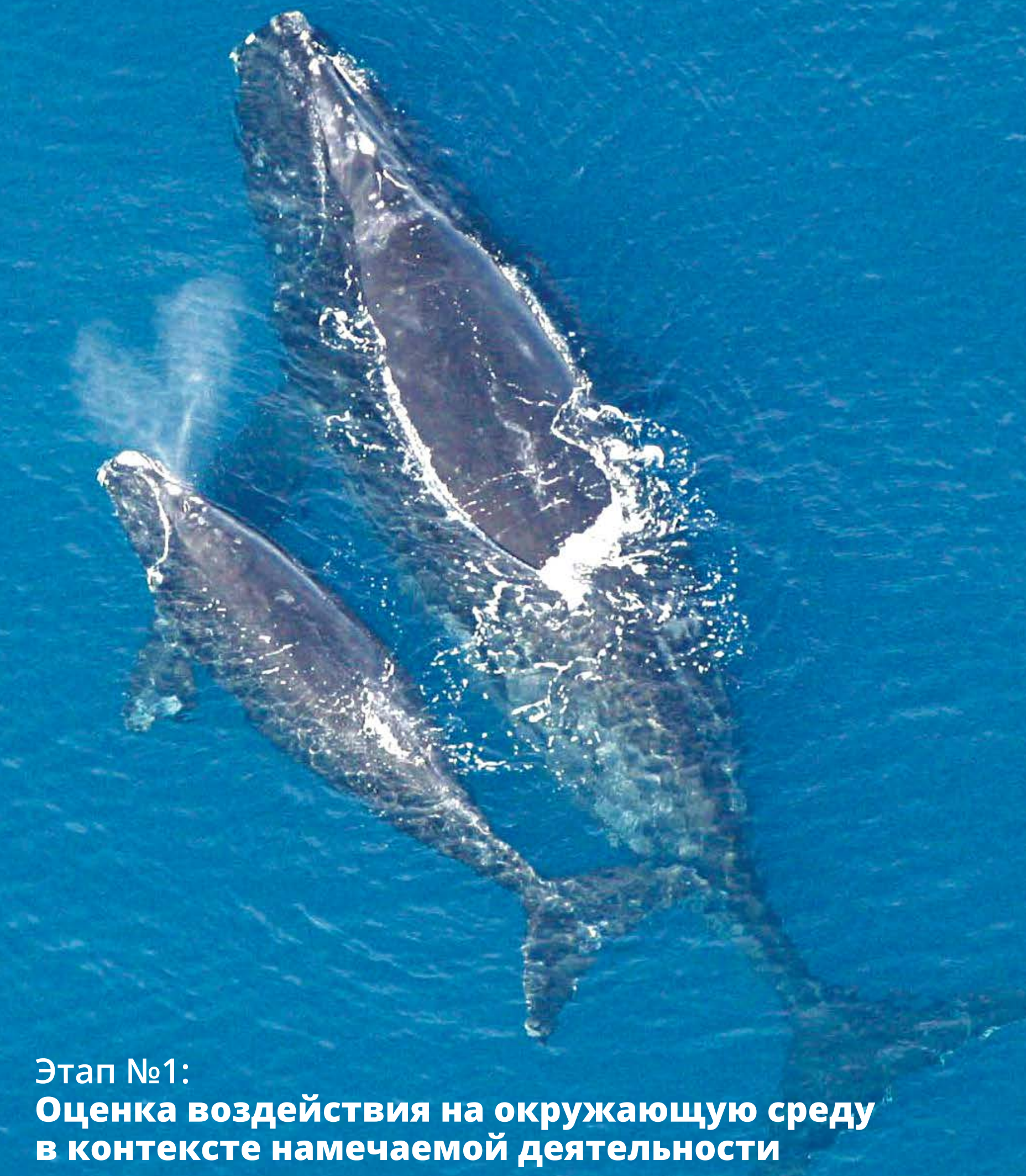

(c) Национальное управление по исследованию океанов и атмосферы (HOAА), Министерство торговли США / В открытом доступе - Фотобиблиотека НОАА 


\section{Обоснование}

Сразу после окончания предварительной оценки операционных, экологических и биологических факторов с целью анализа общего потенциального риска, прежде чем начинать детальное операционное планирование, необходимо в соответствующем масштабе провести оценку воздействия на окружающую среду в контесте намечаемой деятельности. Важно понимать, что первоначальные шаги, описанные в рамках Этапа №1 не включают детальный анализ рисков для окружающей среды с точки зрения конкретной предлагаемой работы. Они скорее отображают общие подходы по оценке воздействия на окружающую среду при проведении геофизических работ, а также по оценке воздействия отдельных компонентов этих работ, что необходимо для проведения детального анализа рисков в отношении окружающей среды. Предлагаемая здесь процедура проведения оценки воздействия включает исходное рассмотрение более общих экологических вопросов с учетом параметров геофизических работ, но также включает подробную и структурированную биологическую и экологическую оценку, которую следует использовать при разработке конкретного плана проведения работ (Этап №2).

В случае с хорошо изученными районами, в которых ранее проводились работы и (или) исследования, подробная оценка будет включать определение и анализ исходных данных, которые должны использоваться для формирования оценки, а также любых доступных данных. В относительно малоизученных районах, где все чаще проводятся геофизические работы, может потребоваться дополнительный и, в некоторых случаях, продолжительный (многолетний) сбор базовых экологических данных для обеспечения наличия достоверной информации в целях проведения оценки, а также для проведения мониторинга и применения мер снижения воздействия.

Менеджеры должны понимать, что наличие надежных исходных данных о состоянии окружающей среды необходимо для эффективного управления риском. В отношении особо уязвимых районов, например местообитаний уязвимых или вымирающих видов, может потребоваться продолжительный мониторинг, например, втечениенесколькихсезоновилилетпередначалом работ(см. Таблицу 1, содержащуюрекомендации по оценке характера исходных данных, а также Пример конкретной практики №1, где рассматривается один из подходов к сбору исходных данных). Помимо этого, данный этап начального планирования и оценки требует самого тщательного анализа характера намечаемых работ. В идеале, описываемые параметры, указанные ниже, должны быть описаны и представлены с использованием стандартизированных параметров и описаний.

Оценка планируемых операций и их потенциального воздействия на конкретные местообитания включает в себя понятия оценки окружающей среды, оценки воздействия на окружающую среду, экспертизы воздействия на окружающую среду или оценки воздействия на окружающую среду и социальную сферу. Понятие оценки воздействия на окружающую среду (ОВОС) появилось в 60-е годы XX века, во время интенсивного промышленного развития, которое совпало с распространением осознания того, что такое развитие может угрожать дикой природе. Целью такой оценки является информирование субъектов, ответственных за принятие решений по поводу допустимости и условий реализации проектов по освоению месторождений, о вероятных последствиях и степени тяжести сопутствующих рисков. Операторы, которые планируют соответствующие работы, часто сталкиваются с необходимостью соблюдения требований о подготовке оценок для подачи в надзорные органы. С момента законодательного закрепления ОВОС в США в рамках Закона от 1969 года о национальной политике в области охраны окружающей среды (Колдвелл, 1988 г.), стандартная процедура подачи ОВОС была принята и включена в правовую и надзорную системы многих стран (например Федеральный реестр США, 43 FR 55994, 29.11.1978 г.; Оценка ЕС о воздействии на окружающую среду, httр:// ec.europa.eu/environmenteia/home.htm; Министерство Новой Зеландии по охране природы, uww.doc.govt.nz/ conservation/marine-and-coastal/seismic-surveys-code-of-conduct; и см. Приложение). Настоящее руководство призвано дополнить и улучшить качество, а также обеспечить преемственность программ по мониторингу и мерам снижения воздействия с акцентом на районы или ситуации, когда наличие исходных данных ограничено. Не меньшую важность это руководство представляет для операторов различных проектов на

Стратегии эффективного планирования в целях управления экологическим риском, связанным с геофизическими и иными исследованиями, направленными на получение графических изображений 
шельфе, применяющих геофизические методы исследований, руководствующихся Стандартами деятельности Международной финансовой корпорации и связанными с ними методических принципов охраны окружающей среды, охраны труда и техники безопасности. В тексте пояснительной записки №9 к Стандарту деятельности № 6 сказано: «В рамках ОВОСС (Оценки воздействия на окруюсююую среду и социальную сферу) базовые исследования должны проводиться в отношении релевантных характеристик биоразнообразия и экосистемных услуг» (в Приложении содержится перечень Стандартов деятельности МФК и ссылки на них).

\section{Элементы передовой практики}

\section{А. Сбор исходных экологических и биологических данных - биотические и абиотические компоненты экосистемы}

\footnotetext{
В данном разделе указываются типы информации, требуемые для выполнения полноценного анализа потенциальных эффектов геофизических работ, как на основе данных о физической среде (поскольку среда влияет на характер исследования и аспекты распространения звука), так и информации о характере присутствия животных. Необходимо проведение натурных исследований биологической среды, а также достаточная характеризачия трендов природной изменчивости, например сезонные факторы или специфика использования местообитаний.
}

В начале планирования конкретных геофизических работ необходимо выявить и проанализировать данные за несколько лет в отношении общих характеристик и природной изменчивости релевантных экосистем района работ (см. Таблицу 1). В случае необходимости, сбор таких данных нужно начать сразу после принятия решения о реализации проекта. Как минимум требуется собрать и проанализировать исходную информацию о вызывающих обеспокоенность видах животных либо на основе непосредственных наблюдений в районе проведения намечаемых работ, либо исходя из разумных предположений, сделанных на основе наблюдений в сходных районах и ситуациях. Нередко сбор и представление такой информации происходит в рамках подготовки ОВОС. Однако предварительная оценка нередко выполняется по менее жестким правилам, поэтому не настолько реперезентативна, насколько могла бы быть. Например, недостаточно знать лишь о том, что в районе проведения работ или в непосредственной близости от него находится вызывающий обеспокоенность видилипопуляцияживотных. Вособенности, когдапроверкадо началапроведения работ дает основания полагать, что геофизические работы могут иметь высокий потенциальный риск, и для правильного планирования и разработки мер снижения воздействия требуется точное понимание сезонной изменчивости встречаемости и плотности распределения животных, их поведения, особенностей размножения, нагула и использования местообитаний. Некоторые операторы серьезно относятся к необходимости наличия исходных данных (см. Пример конкретной практики №2). Помимо этого, информация о физических свойствах района работ (например, температура воды, временные рамки формирования и таяния льда в море, сезонность и сила штормов), а также их влиянии на жизненный цикл и поведение животных (например, рождение детенышей, спаривание, нагул) может указывать на то, что степень воздействия геофизических работ на животных может быть значительно снижена или устранена путем корректировки сроков работ.

\section{Ключевая информация, необходимая для проведения оценки:}

- Выраженная в количественных показателях информация о наличии, распределении, сезонности, поведении, иных стрессовых факторах, специфики использования конкретного района в качестве местообитания самими ОУВ, с применением всех имеющихся источников данных (включая неопубликованные данные при условии проверки надежности данных и наличии соответствующих ссылок).

- Исходная информация может собираться путем тщательных поисков в научных публикациях информации по ОУВ и окружающей среде района работ. Если необходимая информация отсутствует или является неполной, можно использовать информацию о соответствующих ОуВ и (или)

Стратегии эффективного планирования в целях управления экологическим риском, связанным с геофизическими и иными исследованиями, направленными на получение графических изображений 
родственных видах из других районов для дополнения известных данных о видах или популяции, представляющих непосредственный интерес. Например, информация о гренландских китах (Baldena mysticetus) может оказаться релевантной, если район исследования включает местообитание гладких китов (Eubalaena spp). Существующая информация полезна или необходима для построения основы, а также служит руководством для сбора дополнительных данных.

- Определение характеристик экосистемы (например, кормовых объектов), которые могут быть особенно чувствительными к беспокоящему акустическому воздействию и (или) являются ключевыми компонентами местообитания ОУВ.

- Определение физических аспектов окружающей среды, которые, вероятно, будут влиять на ход проведения геофизических работ или деятельности в отношении ОУВ (большинство из которых, если не все из них, скорее всего будут учитываться в ходе планирования работ, однако важно рассматривать их в контексте мер снижения воздействия и мониторинга ОУВ). Среди подобных физических аспектов можно перечислить:

- температуру воды и другие океанографические условия (например, образование ледяного покрова), с точки зрения их влияния на работы и встречаемость ОУВ;

- тип дна и батиметрию, что необходимо для моделирования распространения звука; и

- приливы, в особенности, с точки зрения их влияния на планирование геофизических работ или временные рамки и, соответственно, время осуществления, характер и частоту взаимодействия с ОУВ.

Информация, наличие которой желательно:

- Распределение и схема использования местообитания всеми видами, включая виды, которые не относятся к ОУВ и которые скорее всего будут находиться в местообитании и на которых может оказываться воздействие (например, рыбы, черепахи); такая информация может указывать на стратегию для снижения риска для видов вне категории ОУВ без ущерба для планируемых работ.

Информация, необходимая на данном этапе, также применяется в следующих целях:

1. Оценка риска (Этап № 2.А)

2. Разработка мер снижения воздействия (Этап № 2.В)

3. Разработка программы мониторинга (Этап № 2.С)

4. Оценка эффективности мер снижения воздействия (Этап № 4.А)

\section{Б. Анализ воздействий и рассмотрение альтернатив (необходимо описать все этапы и осуществимые альтернативные стратегии вне зависимости от экономической целесообразности)}

В данном разделе указывается конкретная информация о различных элементах геофизических работ, включая альтернативные варианты и сопутствующие риски различной степени воздействия на окружающую среду. Целью Этапа №1 является оценка различных вариантов в относительно общем плане с целью уточнения аспектов и участков проведения геофизических работ (по мере наличия различных вариантов), что, таким образом, позволяет (вконтекстеЭтапа №2)провестинадежную оценкупотенциальныхэффектовсейсморазведки с учетом как информации о самих работах, так и ОУВ, на которые может оказываться воздействие. Некоторая информация, используемая на данном Этапе, схожа с информацией в контексте Этапа №2, где применяется в отношении элементов и вариантов проведения геофизических работ с точки зрения анализа потенциального риска. 
1. Описание параметров излучения источников звука, судов и т.п., включая:

- количество и объем пневмопушек в составе батареи или, в случае с некоторыми другими звуковыми источниками, подробные технические параметры источника;

- моделирование акустического источника, например, направленность, общая мощность источника; и

- общеезвуковоеизлучение(количество иуровень активности)всехсудов, задействованныхвгеофизических работах.

\section{2. Определение инструментов для моделирования распространения} звука и анализа воздействия, алгоритмы и условия, включая:

- элементы для моделирования, такие как:

- данные по батиметрии;

- данные о температуре воды и профилях скорости распространения звука в определенное время года; и

- характеристики источника по всем составляющим источникам звука в объеме, достаточном для проведения моделирования.

- $\quad$ характеристики передвижений животных, включая условия, при которых конкретные виды проявляют реакции уклонения, избегания, любопытства и т.п.

3. Перечень и оценка альтернатив, которые могут минимизировать общее шумовое воздействие на ОУВ, в особенности, в отношении определения способов сокращения общей площади распространения шума от геофизических работ посредством анализа или обработки имеющихся данных. Среди вариантов для рассмотрения можно перечислить:

- тип источника звука - приветствуется рассмотрение существующихи новых технологий для геофизических исследований (например, морской вибросейсмический метод), которые могут обладать пониженным уровнем звукового излучения;

- объем источника звука - мощность источника, пересчитанная с учетом требуемого проникновения в недра;

- с совместные исследования - в районах, где работы проводятся несколькими компаниями одновременно, можно осуществить значительную экономию средств и снизить воздействие на окружающую среду без ущерба для получаемых данных и их качества; данный метод находит все большее распространение во всем мире;

- площадь проведения геофизических работ - установленные границы рассчитаны исключительно на охват тех районов, в которых крайне необходимо осуществить сбор данных;

- изменения в отношении района проведения геофизических работ, временных параметров (например, времени года), а также продолжительности с целью сокращения объема или отказа от проведения работ в пределах критического местообитания ОУВ или во время периодов особой уязвимости ОУВ;

- минимизацияприменениясамыхгромкихзвуковыхисточниковвпериодпониженнойвидимости(например, ночное время суток, туман), обеспечивая при этом баланс между данной мерой и осуществлением главной цели, которая заключается в сокращении общей продолжительности геофизических работ;

- $\quad$ рассмотрение возможности применения пассивных (например прослушивание среды для обнаружения звуков, издаваемых животными) и активных (например использование управляемого источника звука для обнаружения присутствия животных) акустических систем как для снижения воздействия, так и для мониторинга;

- $\quad$ рассмотрение возможности применения воздушной съемки ОУВ (спомощью пилотируемыхи беспилотных аппаратов) в условиях, где как оцениваемый риск от проведения геофизических работ, так и вероятность обнаружения ОУВ являются относительно высоки; а также

- $\quad$ рассмотрение возможности применения новых и совершенствуемых технологий, таких как наблюдение с помощью тепловизоров и спутников для обнаружения животных, в основном, с целью реализации мер снижения воздействия, но также для мониторинга в определенных условиях.

Стратегии эффективного планирования в целях управления экологическим риском, связанным с геофизическими и иными исследованиями, направленными на получение графических изображений 


\section{С. Вовлечение заинтересованных сторон}

В соответствии с данными, указанными на Рис. 2, некоторые компании проводят направленные оценки в отношении потенциальных воздействий на социальную сферу в контексте намечамоей деятельности. Геофизические работы должны быть неотъемлемой частью оценки риска в социальной сфере с целью должного соблюдения интересов всех заинтересованных сторон, несмотря на то, что такие работы не учитываются или не включены в процедуру получения ОВОС. Заинтересованные стороны - это частные лица, НПО или государственные органы, которые обладают определенным интересом или находятся под потенциальным воздействием деятельности компании. В то время как сами компании в конечном счете отвечают за интеграцию требований по проведению геофизических работ и выполнение сопутствующих требований по охране окружающей среды, вовлечение заинтересованных сторон на самой ранней стадии проекта может сыграть решающую роль в его успешной реализации. Начиная от надзорных органов и заканчивая НПО, которые занимаются вопросами, связанными с ОУВ в конкретном районе, вышеуказанные группы и лица должны принимать непосредственное участие, чтобы понимать реальные и потенциальные воздействия деятельности и быть в курсе интересов и опасений друг друга. Участие заинтересованных сторон также важно для понимания того, как местные общины используют природные ресурсы, например, в контексте местного рыболовного промысла или экологического туризма. Вовлечение заинтересованных сторон крайне важно для ответственного планирования (более подробную информацию об подходах и рекомендациях относительно участия заинтересованных сторон можно найти в соответствующих источниках: ARPEL (Региональная ассоциация производителей нефти и газа в странах Латинской Америки и Карибского бассейна, 2011 г., IOGP (Международная ассоциация производителей нефти и газа, 2014 г.), МФК (Международная финансовая корпорация, 2007 г.) и др.

Не бывает двух совершенно одинаковых геофизических исследований в плане площади, объема и мощности источника, присутствия видов животных, а также их плотности и распределения, глубины воды, продолжительности, расстояния от берега и т.д. Таким образом, невозможно подготовить единый стандартный протокол, подходящий для планирования всех геофизических работ. Таким образом, необходимо индивидуально разрабатывать конкретные меры снижения воздействия и мониторинга для каждого геофизического исследования и включать их в план по снижению воздействия и программу мониторинга. С целью получения наилучших результатов, ответственные операторы часто прибегают к разработке своих планов на основе широкого сотрудничества, возглавляемого представителями компании и с учетом мнений заинтересованных субъектов. Критерии воздействия представляют собой важный элемент, требующий согласования и, нередко, продолжительных обсуждений. Разработка правил проведения работ на основе допустимого воздействия на животных требует рассмотрения мнений заинтересованных сторон, например, в части обеспечения выполнения критериев, установленные профильным надзорным органом. Такие критерии воздействия, а также все прочие компоненты плана по снижению воздействия и мониторингу, обсуждаются в рамках Этапа №2 ниже.

Стратегии эффективного планирования в целях управления экологическим риском, связанным с геофизическими и иными исследованиями, направленными на получение графических изображений 


\section{Передовая практика №1:}

\section{Базовый мониторинг и вовлечение заинтересованных сторон - программы компании «Шелл» на Аляске}

Ключевые элементы Этапа №1 подразумевают вовлечение заинтересованных сторон и систематический сбор исходных экологических и биологических данных касательно места проведения геофизических работ и деятельности по освоению месторождения. Данные основополагающие компоненты эффективного планирования были отработаны с различной степенью успешности в ходе предшествующих геофизических работ с целью определения важных биологических элементов среды, на которую оказывается воздействие, и ключевых параметров предлагаемых геофизических работ, а также с целью побудить компании к открытости в работе с местным населением и общинами.

Недавний пример отраслевой интегрированной разведочной программы, в рамках которой были ответственным образом успешно реализованы подобные меры - программа по мониторингу и снижению воздействия на морских млекопитающих, разработанная и осуществленная компанией «Шелл» в Чукотском море1. На основе проведенных ранее мероприятий в море Бофорта у берегов Аляски компанией «Шелл» была разработана полностью интегрированная и комплексная программа, включающая планирование, реализацию и анализ, которая включала комплексные и систематические процедуры верификации откалиброванного источникав отношениивсехзвуковыхисточниковсейсморазведки. Такиеданные, собранныесиспользованием контролируемых измерений, позволили получить подробную и точную информацию о звуках, которые оказывали бы воздействие на окружающую среду во время проведения геофизических операций, а также их распространении в зависимости от расстояний. Данная информация часто отсутствует несмотря на то, что ее наличие требуется в рамках оценки воздействия на окружающую среду (Этап №2).

Помимо этого, значительные усилия были направлены на разработку базового мониторинга природных и биологических элементов в районах проведения геофизических операций. Данные усилия включают проведение в течение многих лет мониторинга со специально сформулированными целями в отношении конкретных видов животных на основе сочетания визуальных наблюдений, акустического мониторинга и экологических измерений. Базовый мониторинг проводился с помощью ряда механизмов, включая подрядчиков, работа которых оплачивалась напрямую компанией «Шелл» (Shell), вовлечение других отраслевых операторов и в совместные усилия по мониторингу и содействие с их стороны для того, чтобы получить более четкое представление об акватории за пределами непосредственного района проведения геофизических работ, а также поддержку программ по базовому мониторингу в партнерстве с местными общинами и коренными народами². Подход компании «Шелл» к обязательному базовому мониторингу заключался в использовании надежных методов и четко сформулированных целей мониторинга в течение многих лет до начала геофизических работ, в сотрудничестве с различными заинтересованными сторонами, включая субъектов из частного сектора и исследователей, партнеров по отрасли и местное население. Таким образом, в рамках данной программы удалось добиться сбора достоверных базовых данных и, в то же время, обеспечить открытость во взаимодействии с заинтересованными сторонами.

\footnotetext{
1 http://www.nmfs.noaa.gov/pr/permits/incidental/oilgas/shell_2015_revised4mp.pdf

2 http://www.north-slope.org/departments/wildlife-management/nsb-shell-baseline-studies-program
} 


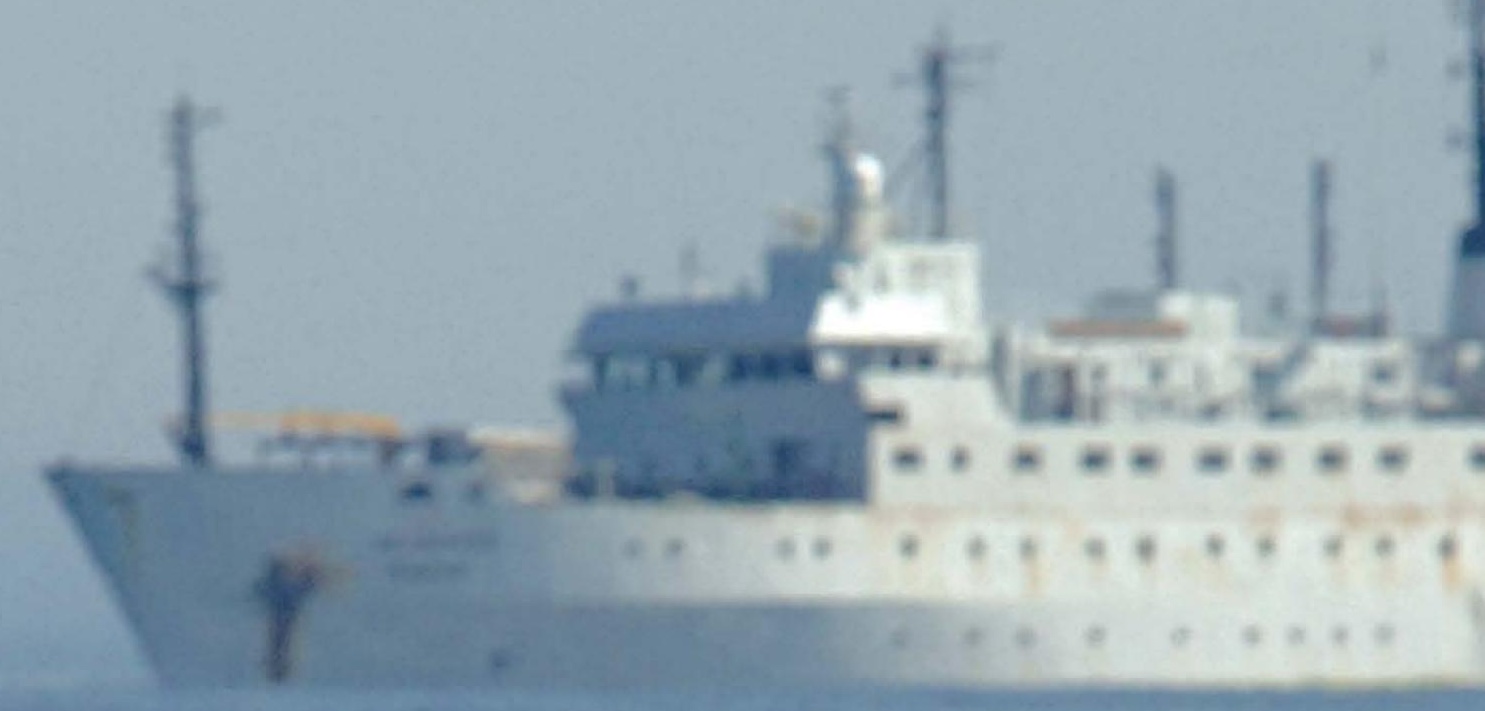

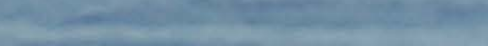

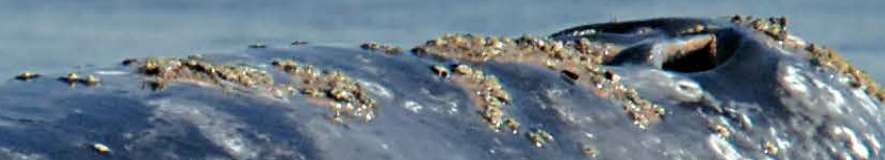

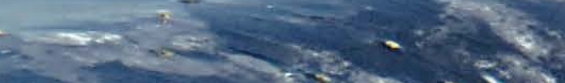

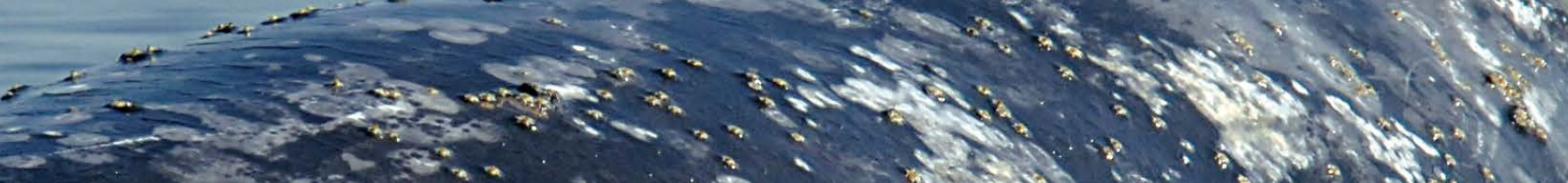

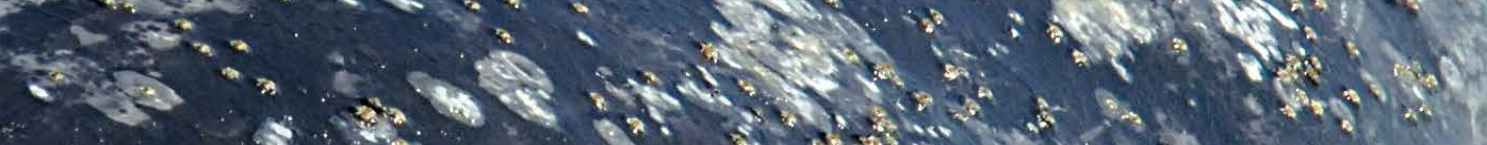

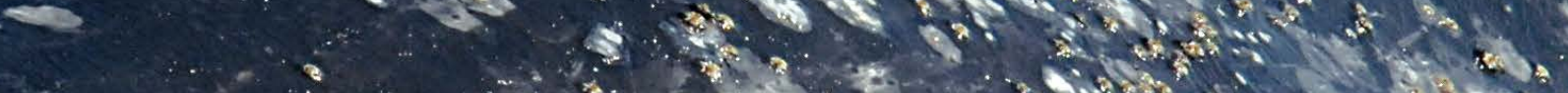

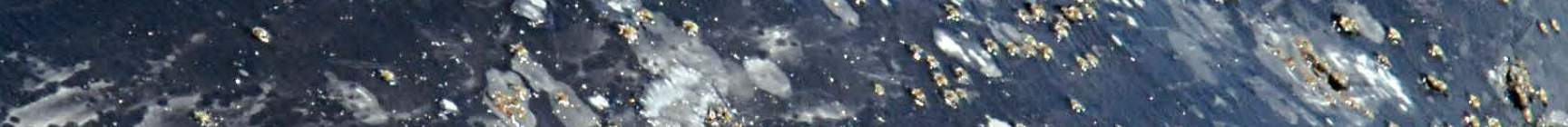

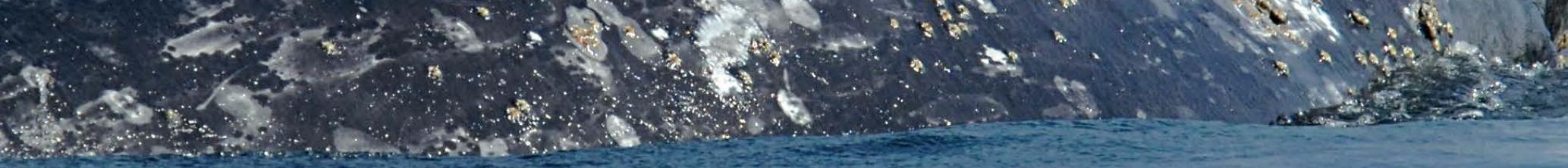

Этап №2:

Оценка риска и планирование 


\section{Обоснование}

Как уже обсуждалось ранее, для комплексной реализации планов по охране окружающей среды для проведения геофизических работ требуется информация в отношении базовых экологических факторов, потенциальное беспокоящее воздействие от проводимых геофизических исследований, включая отдельные аспекты намечаемых работ. Принимая во внимание наличие значительного объема информации об окружающей среде (распределение и поведение основных видов и т.п.) и характере намечаемых работ (параметры источника звука, продолжительность геофизических работ, пространственное распределение и т.п.), необходимо провести структурированную оценку риска от потенциальных эффектов (вместо более упрощенной системы определения «на основе порога чувствительности» в соответствии с требованиями в некоторых странах, например, в США).

В данной оценке необходимо однозначно рассмотреть непосредственную физическую и поведенческую реакцию наблюдаемых видов от намечаемых геофизических работ. Совершенствование научных знаний в области определения того, как шум от различных источников, включая геофизические работы, влияет на слух и поведение морских млекопитающих, значительно улучшило возможности для проведения оценки потенциального беспокоящего воздействия. В рамках более детализированных аналитических подходов к оценке различных эффектов применяются вероятностные функции и учитываются элементы контекста воздействия, такие как относительное расстояние до источников и их перемещение, что выходит за пределы простого определения уровня звукового воздействия (примеры приведены в Приложении №1).

На основе результатов, полученныхв рамкахЭтапа №1, возможно проведение структурного анализапотенциальных рисков сучетом величины прогнозируемых физическихи поведенческих эффектов от геофизических работ, а также от иной хозяйственной деятельности, в контексте характеристик популяции и жизненного цикла рассматриваемого вида, что позволяет провести оценку рисков в контексте биологической значимости вместо простого подсчета числа животных, которые получат физические травмы или подвергнутся беспокоящему воздействию. Более того, можно учитывать агрегированные, синергические и кумулятивные эффекты намечаемых работ в контексте иной хозяйственной деятельности и экологических проблем в более широком смысле (изменения климата и т.п.). Оценка риска для конкретного вида может быть проведена вместе с другими релевантными параметрами, такими как популяционные тенденции и статус, в контексте локально применимых нормативных требований и социальных нужд, чтобы разработать эффективные цели и стратегии мониторинга и мер снижения воздействия. Такая деятельность наиболее эффективна при соблюдения принципа открытости и прозрачности, а также внедрении измеримых показателей, которые позволяют провести анализ эффективности выполнения работ (в рамках Этапа №3) и заложить основу для обоснованных оценок будущих работ (Этап №4).

\section{Элементы передовой практики}

\section{А. Оценка рисков, связанных с намечаемыми работами, и рассмотрение альтернатив}

Одним из самых важных аспектов ответственного подхода является структурированная и систематическая оценка рисков намечаемых геофизических работ. Как упоминалось выше, существуют отраслевые подходы, в которыхприменяетсяподобный метод. Вероятностная структура, описанная в настоящем документе, достаточно дифференцирована в плане анализа результатов, чтобы генерировать относительные (не бинарные) оценки рисков с учетом имеющейся информации и существующих трендов в районе проведения работ в отношении компонентов намечаемых геофизических исследований. На основе проведенных оценок риска возможно определить меры, которые, посредством мониторинга, могут доказать свою необходимость и приемлемость, а также потребность в осуществлении мероприятий по снижению воздействия в случае необходимости. Как

Стратегии эффективного планирования в целях управления экологическим риском, связанным с геофизическими и иными исследованиями, направленными на получение графических изображений 
отмечалось выше, понятие оценки риска часто применяется в рамках принятия решений коммерческого свойства, а также в стандартах деятельности предприятий, занимающихся разведкой и добычей, в контексте работ, проводимых на шельфе. Данное понятие находит все более частое применение во всем мире. В каждом конкретном случае выбранный применимый подход, а также отдельные аспекты, в частности, особенности нормативно-правового регулирования, могут отличаться в зависимости от места проведения работ, однако базовые элементы передовой практики, описаные ниже, остаются неизменны.

Количественная оценка риска может быть проведена на основе информации, полученной в рамках Этапа №.1.А и Этапа №1.Б. Может потребоваться дополнительное внимание в случае отсутствия необходимой информации или относительно высокого уровня неопределенности. Тем не менее, можно применить разумные усилия для экстраполяции имеющихся данных прямых измерений для определения рисков и помощи в определении адекватных мер по снижению воздействия и мониторингу (Этап № 2.Б, 2.В). В некоторых случаях, можно свериться с применимыми данными из открытых источников, хотя, в ряде случаев, компании предпочитают тратить время и усилия на сбор собственных данных о воздействиях до начала геофизических исследований, а также во время их проведения и после них (см. Передовую практику №3). Подход к проведению анализа, предусмотренный в данном случае, призван быть комплексным и, в то же время, конструктивным. Проведение анализа должно включать следующие элементы:

\section{Примеры используемых данных}

- Характеристики геофизических работ (из Этапа №1):

- предполагаемый географический район, включая пространственные особенности проведения геофизических работ;

- общая предполагаемая продолжительность и время проведения (время года); и

- характеристика источника звука (уровень звукового излучения, спектр частот, направленность).

- Экологические (небиологические) характеристики:

- глубина и батиметрия предлагаемого района проведения геофизических работ (включая качество данных);

- профили скорости распространения звука, характерные для предполагаемых районов и сроков;

- состав осадочных пород и другие характеристики дна (для применения в рамках моделирования акустического распространения);

- наличие других геофизических работ и общее беспокоящее воздействие техногенного характера в районе проведения геофизических работ; и

- типичные погодные и океанографические условия, а также продолжительность дня на протяжении проведения сейсморазведки (поскольку эти факторы могут повлиять на эффективность мониторинга и снижения воздействия).

- Биологические/экологические характеристики:

- распределение и плотность основных видов, присутствующих во время проведения геофизических работ. Значительный объем исходных данных требуется для понимания ожидаемого распределения и плотности данных видов и сопутствующей вариабельности;

- экологические взаимодействия и факторы, влияющие на распределение и плотность кормовых объектов для основных видов (в случае проведения геофизических работ в самом нагульном ареале или рядом с ним); а также

- характерное поведение видов, присутстве которых наиболее вероятно во время проведения геофизических работ, в типичной ситуации (при отсутствии беспокоящего воздействия) и реакция данных видов на шум для применения при моделировании передвижений животных.

Стратегии эффективного планирования в целях управления экологическим риском, связанным с геофизическими и иными исследованиями, направленными на получение графических изображений 


\section{Оценка воздействия}

- Моделирование распределения животных и их передвижений, включая:

- присутствие типичных видов, групповую структуру и базовое поведение, применяемые для определения ожидаемого распределения в заданном районе в отсутствие беспокоящего воздействия; а также

- поведенческие реакции на шум (уклонение, любопытство и т.п.), применяемые для анализа воздействия в рамках сценариев проведения геофизических работ.

- Моделирование акустического воздействия, которое учитывает вводимые параметры, перечисленные выше, а также передвижения и реакции животных, для определения среднего и максимального шумового воздействия в районе проведения работ с учетом слуховых особенностей конкретных видов (например, функции частотной коррекции).

\section{Анализ потенциальных эффектов (критерии воздействия)}

Сложно рекомендовать конкретные критерии воздействия, поскольку их значения меняются по мере изучения реакции и физиологии животных; более того, критерии и ихприменение отличаются в зависимости от страны. В отсутствие критериев, закрепленных национальными нормативно-правовыми актами, предлагается ссылаться на опубликованные критерии воздействия (Саутхол и др., 2007 г.) и результаты последних исследований по данной проблематике (см. Приложение).

- критические эффекты:

- Применение юридически закрепленных критериев шумового воздействия для получения количественной оценки потенциального физического воздействия на слух (ВПС/ППС), а также физиологической нагрузки;

- Применение юридически закрепленных критериев шумового воздействия для получения количественной оценки (желательно, вероятностного характера) поведенческой реакции при наличии таковой.

- Агрегированные/постоянные эффекты:

- Анализ воздействия намечаемых геофизических работ в контексте других осуществляемых или ожидаемых видов хозяйственной деятельности в заданном районе.

- Проведение количественной оценки потенциальных маскирующих эффектов на передачу звука;

- Учет вероятности широкомасштабного беспокоящего воздействия ввиду проведения других работ. В последнее время наблюдается некоторый прогресс в отношении разработки методов такого учета, но, скорее всего, потребуется качественная оценка данных эффектов, по крайней мере, до определенной степени, учитывая существующий уровень научных знаний. В данной области требуется координация, сотрудничество и обмен данными между представителями отрасли, государственными ведомствами и учеными, что несомненно обеспечит наличие общих выгод.

\section{Оценка риска в отношении вероятности ожидаемой реакции}

- Оценка риска в контексте демографии популяции:

- использование результатов моделирования популяции для оценки относительных (а не бинарных) масштабов критических эффектов; популяционные модели прогнозируют размер и здоровье популяции при различных сценариях;

- учетпараметровжизненногоциклапо конкретным видам, популяционнойтенденцииипотенциальных агрегированных или постоянных эффектов (например экранирование) в систему оценки риска.

- Проведение интегрированной оценки риска потенциальных эффектов:

- использование прогнозных значений риска для критических и агрегированных или постоянных эффектов, чтобы определить масштабы эффектов на уровне популяции в части выживания и размножения;

Стратегии эффективного планирования в целях управления экологическим риском, связанным с геофизическими и иными исследованиями, направленными на получение графических изображений 
- Учет неопределенностей путем непосредственной оценки достаточности вспомогательной информации (например, отсутствует, является косвенной, непосредственные данные в ограниченном объеме или непосредственные данные в полном объеме).

- Применение мер снижения воздействия и мониторинга, предусмотренные законодательством, с учетом рисков.

\author{
Информация, необходимая на данном этапе, также \\ будет применяется в следующих целях: \\ 1. Разработка мер снижения воздействия (Этап №2.Б) \\ 2. Разработка программы мониторинга (Этап № 2.Б)
}

\title{
Б. Идентификация мер по снижению воздействий
}

При проведении детальной оценки рисков для основных видов в результате намечаемых геофизических работ можно без особых трудностей идентифицировать, какие специально адаптированные меры по снижению воздействия потребуются. Существующие природоохранные требования для района проведения геофизических работ могут помочь сделать правильные выводы в отношении необходимых мер, выявленных на основе оценки риска; разумеется, операторам необходимо следовать требованиям нормативно-правовых актов. В данном разделе определяются и рассматриваютсяподходы куменьшениюпотенциальныхвоздействий от геофизических работ. Здесь учитываются меры, применяемые в разных регионах мира, что требует значительного заблаговременного внимания со стороны специалистов по планированию (см. Приложение).

1. Определение целей в контексте снижения воздействия на основе исходных данных, оценки риска намечаемых работ и применимых нормативно-правовых требований. Среди них можно перечислить следующие:

- Определение сезонного присутствия и плотности ОУВ и соответствующая корректировка работ, чтобы проводить их в периоды времени, не являющиеся особо важными с биологической точки зрения;

- Установление максимально допустимых уровней воздействия для: (1) охраняемых видов, включая более уязвимые особи (например, пары «мать-детеныш»); (2) любых других видов, т.е. допустимый уровень воздействия может варьироваться в зависимости от степени природоохранных требований;

- Определение критериев для снижения мощности и (или) отключения источника звука на основе предельно допустимых уровней воздействия;

- Определение дополнительных требований к снижению воздействия, включая ограничения эксплуатации или отключение источников звука в целях снижения воздействия.

2. Разработка оперативных протоколов для обнаружения ОУВ с целью реализации мер снижения воздействия. Такие протоколы можно интегрировать в мониторинг и они могут включать любые или все нижеперечисленные элементы (объем и интеграция которых будут зависеть от требований и особенностей района работ):

- регулярный визуальный мониторинг с судна или берега;

- акустический мониторинг в реальном времени пассивного и (или) (в некоторых случаях) активного типа;

- визуальные наблюдения с воздуха; и

- применение оборудования с инфракрасным излучением, приборов ночного видения и (или) других технологий.

3. Обеспечение необходимой степени подготовки и уровня координации усилий, включая:

- привлечение опытного и тщательно подготовленного полевого персонала; и 
- обеспечение интегрированной командно-административной матрицы с назначением одного лица, ответственного за принятие решений, касающихся реализации мер снижения воздействия в полевых условиях

4. Обеспечение прозрачности процедур составления ОВОС (в соответствии с типовыми требованиями) путем предоставления в открытом доступе информации о мерах и протоколах снижения воздействия и, при конкретных обстоятельствах, привлечение независимого наблюдателя для оценки реализации и эффективности планов.

\section{С. Разработка стратегии и методов мониторинга для применения до, во время и после работ}

Применяя указанную выше оценку риска в сочетании с мерами и требованиями по снижению воздействия, необходимо разработать методы мониторинга в реальном времени и с использованием автономных записывающих устройств. Также необходимо идентифицировать и соблюдать нормативно-правовые требования в отношении района проведения геофизических работ в контексте составления отчетов после завершения работ.

В настоящем разделе приводятся ссылки и рассматриваются различные подходы к мониторингу, которые применяются в разных странах (см. Приложение І). Масштаб и интенсивность их применимости и выполнения будут разными для единичных, небольших исследований и для масштабных геофизических кампаний, осуществляемых в рамках крупных проектов по освоению месторождений, что в основном определяется в ходе предварительной оценки до начала Этапа №1. Необходимо учитывать, что для получения наилучшего результата требуется привлечение квалифицированных наблюдателей за морскими млекопитающими (НМм) для проведения мероприятий по мониторингу и снижению воздействия (см. ссылку на текущие инструкции в отношении НММ в Приложении). Подходы к мониторингу включают:

1. Интеграцию технических средств и протоколов мониторинга с мероприятиями по снижению воздействия в реальном времени (Этап № 2.Б); данные из таких источников также должны сохранятся надлежащим образом;

2. Разработку методов мониторинга, обладающих достаточным разрешением для получения соответствующей информации, с целью:

- обнаружения изменений в ключевых базовых экологических параметрах, учитывая естественную изменчивость (Этап № 1.А), и, таким образом, провести оценку воздействия на виды биоты, в особенности на ОУВ и (или) уязвимые популяции;

- в конечном итоге, применения данных мониторинга для оценки эффективности мер снижения воздействия (Этап № 2.Б);

- ликвидации пробелов в данных и информации; и

- развития долгосрочного базового мониторинга для совершенствования научных знаний.

3. Разработку оперативных протоколов мониторинга с использованием автономных записывающих приборов в отношении всех ОУВ. Данные протоколы (с планированием) могут быть интегрированы с методами мониторинга в реальном времени, которые применяются для реализации мер по снижению воздействия. Такие протоколы могут включать любые или все перечисленные компоненты (объем и возможность интеграции которых зависят от локальных требований и условий):

- комплексная интеграция визуального мониторинга с судов, берега и с воздуха (при наличии такового);

- автономный акустический мониторинг пассивного и (или) (в некоторых случаях) активного характера;

- систематическая отчетность о погодных и океанических условиях с различных регистрирующих приборов; и

Стратегии эффективного планирования в целях управления экологическим риском, связанным с геофизическими и иными исследованиями, направленными на получение графических изображений 
- систематическая отчетность о всех периодах работ с активными звуковыми источниками и судами, а также периодах с иной известной антропогенной беспокоящей деятельностью в районе проведения геофизических работ.

4. Разработку комплексного плана отчетности в отношении:

- обнаружений, произведенных с применением различных методов в условиях, когда требовалось или не требовалось уменьшение мощности или отключение источника шума; и

- всех данных наблюдений за поведением ОУВ во время шумового воздействия или его отсутствия в ходе проведения геофизических работ

\author{
Информация, необходимая на данном этапе, также \\ применяется в следующих целях: \\ 1. Реализация мер снижения воздействия (Этап № 3.A); \\ 2. Оценка мер снижения воздействия (Этап № 4); \\ 3. Разработка мер снижения воздействия в будущем (Этап № 4).
}




\section{Передовая практика №2:}

\section{Проведение государственного мониторинга до начала осуществления разведочно-добывающей деятельности в Ирландии}

В 2014 году Министерством связи, энергетики и природных ресурсов Ирландии совместно с Министерством искусства, наследия и гэлтахт (Управление национальными парками и заповедниками) была введена обширная программа по сбору данных (ObSERVE). Программа была разработана для получения новых базовых данных с целью заполнить имеющиеся пробелы в данных об охраняемых морских видах и районах в ключевых морских акваториях. Программа была создана с целью возможной выдачи лицензий на разведку нефтегазовых месторождений, в частности в некоторых отдаленных акваториях Атлантического океана, в отношении которых информация о присутствии китообразных в течение года отсутствовала или имелась в крайне ограниченном объеме. Существует два компонента данной работы: первый компонент представляет собой программу для получения акустических данных с применением автономных записывающих устройств и акустические исследования с буксируемыми устройствами, которые охватывают акваторию внешнего континентального шельфа, склон континентальной отмели и глубоководные океанические акватории, принадлежащие Ирландии. Второй компонент включает ряд воздушных наблюдений на наличие китообразных и морских птиц в разные времена года. Такая программа представляет собой образцовый пример, когда правительство берет на себя ответственность за сбор базовых данных до предоставления возможности проведения работ по разведке и освоению нефтегазовых месторождений.

\footnotetext{
1 http://nww.dcenr.gov.ie/natural-resources/ga-ie/Oil-Gas-Exploration-Production/Pages/ObSERVE-Programme.aspx http://mwn.observe-acoustic.ie/ www.observe-aerial.ie
}

Стратегии эффективного планирования в целях управления экологическим риском, связанным с геофизическими и иными исследованиями, направленными на получение графических изображений 


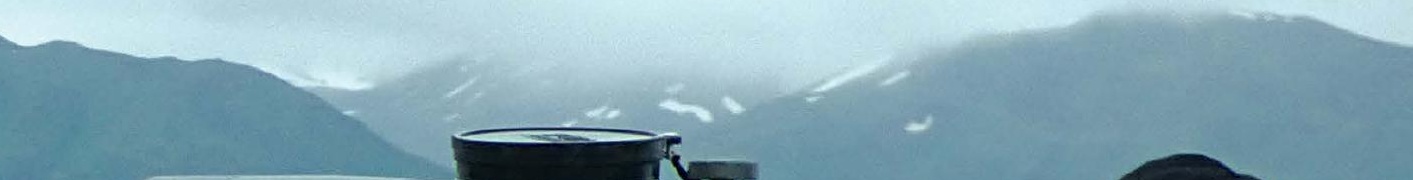

Этап №3:

0. gунествление мер по снижению воздейс вия и проведенте мониторинга работ 


\section{Обоснование}

Подробный план осуществления мер по снижению воздействия и мониторинга в ходе проведения работ, основанный на оценке рисков для определенных видов животных и учете характера деятельности, лучше всего осуществлять в виде стандартного компонента геофизических работ (см. Передовую практику №4). Необходимо наличие в полевых условиях отлаженной системы связи с достаточными резервными средствами с целью обеспечения последовательного и эффективного выполнения мер по снижению воздействия, а также своевременного сбора и анализа данных по мониторингу в реальном времени и с помощью автономных записывающих устройств.

Возможно наличие конфликта двух или более приоритетных задач, которые затрудняют способность (или готовность) оператора реализовывать определенные меры снижения воздействия. K примеру, вполне разумно воздерживаться от проведения геофизических работ в ночное время или в условиях ограниченной видимости ввиду сложности или невозможности обнаружения животных визуальным способом; однако такое ограничение может в итоге привести к значительному увеличению общей продолжительности геофизических работ, включая при этом количество случаев беспокоящего воздействия. Следовательно, отказ от осуществления работ ночью увеличит общую продолжительность геофизических работ, хотя это необязательно должно приводить к увеличению времени воздействия. Моделирование общего воздействия поможет оценить целесообразность подобных компромиссных вариантов. Также важно понимать, что несмотря на согласованное рассмотрение мер снижения воздействия и мониторинга в контексте процедур и планов работ, эти понятия никак не являются идентичными. Разумеется, некоторые методы дистанционных измерений и сбора данных, применяемые как для снижения воздействия, так и мониторинга, могут быть идентичными (пассивная акустика, визуальные наблюдения и т.п.). Тем не менее, в то время как снижение воздействия осуществляется на основе методов мониторинга, в особенности, в режиме реального времени, сам мониторинг требует сбора данных автономными записывающими устройствами, а также систематического мониторинга проводимых работ.

Мониторинг требуется рассматривать в качестве фундаментального аспекта в рамках рабочих задач и протоколов, в особенности, в контексте методов непрерывного сбора данных (таких как пассивная акустика), которые не зависят ни от погодных, ни от различных океанических условий. Продолжительный мониторинг работ проводится на основе оценки риска, осуществляемой в рамках Этапа № 2.А, и направлен на решение ключевых вопросов; в ходе мониторинга также должны соблюдаться конкретные протоколы и осуществляться запись, сохранение и дублирование информации (наличие резервных копий). В некоторых условиях, в особенности, когда речь идет об ОУВ или уязвимых районах, следует рассмотреть возможность привлечения независимого наблюдателя, который бы представил объективные отчеты об эффективности и действенности мониторинга и мер снижения воздействия. Также важно помнить о необходимости обмена экологическими данными между всеми сторонами, соответственно, на такие данные не должны распространяться ограничения, связанные с правами собственности. Обмен данными обеспечивает прозрачность и позволяет сократить объем собираемых данных, которые потребуются операторам предстоящих геофизических работ.

\section{Элементы передовой практики}

\section{А. Применение мер по снижению воздействия в ходе выполнения работ}

Этап №2 охватывает аспекты снижения воздействия, которые определяются на этапе планирования, что включает учет времени проведения геофизических работ, характеристики источника и других элементов работ, для которых разрабатываются меры снижения сопутствующих экологических рисков. Однако на этапе

Стратегии эффективного планирования в целях управления экологическим риском, связанным с геофизическими и иными исследованиями, направленными на получение графических изображений 
проведения работ, непосредственно до самого начала геофизических работ и уже непосредственно в ходе самих работ, необходимо дальнейшее рассмотрение временных рамок и режима работы источника звука для выполнения мер по снижению воздействия в реальном времени (т.е. в полевых условиях по мере проведения работ).

\section{В. Применение мер по снижению воздействия в реальном времени}

В процессе оценки риска, указанном выше (Этап № 2.А), проявляется определенная сложность, связанная с проведением геофизических работ в естественных экосистемах. Тем не менее, в отношении мер снижения воздействия требуются четкие и относительно несложные протоколы снижения воздействия для начала, остановки или прекращения работ на основе ясно сформулированных критериев и отлаженных средств связи. В то время как снижение прямых негативных воздействий, таких как физические увечья или летальный исход является приоритетом, не менее важны меры по снижению воздействия с целью предотвращения, ограничения или уменьшения беспокоящего воздействия.

В настоящем разделе (и Приложении) указываются конкретные элементы и подходы к применению мер по снижению воздействия и мониторинга в ходе проведения работ. Многие компоненты уже были проиллюстрированы и представлены в работе Новачека и соавторов (2013 г.), однако в данном документе также рассматриваются возможные требования в ситуациях с менее тщательной оценкой риска (и, возможно, с меньшим объемом ресурсов). Меры по снижению воздействия, требуемые в соответствии с применимыми нормами права, внутренние правила и глобальные стандарты деятельности компании, а также уровни риска, которые считаются приемлемыми, будут несомненно влиять на характер, количество и сложность элементов разрабатываемых протоколов. Для выполнения мер по снижению воздействия необходимы:

- $\quad$ Письменные протоколы на основе ожидаемых сценариев, заблаговременно изученные, отработанные и понятые ответственными исполнителями работ:

- Предоставить протоколы полевым командам задолго до проведения работ, включая условия, при которых работы можно начинать, продолжать или вносить в них коррективы, а также останавливать или прекращать их на основе критериев, указанных на Этапе № 2.Б;

- Провести инструктаж для полевого персонала для его ознакомления с протоколами, оборудованием и регистрацией/сохранением данных - это может включать имитацию реальных сценариев;

- Точно определить центральный пункт связи (уруководителя или вцентреуправления)сполномочиями на приостановку работ (распоряжения о снижении мощности или отключении источника звука);

- Организовать систему, в соответствии с которой команды, отвечающие за обнаружение животных в реальном времени, должны докладывать напрямую в центр управления;

- Разработать и выполнять четкую и последовательную систему отчетности о трудозатратах и наблюдениях, включая соблюдение операторами и командами по мониторингу в реальном времени распоряжений руководителя или центра управления об остановке работ и других мерах;

- Назначить контактное лицо в соответствии с протоколами (например специалиста по акустике), с которым можно связаться в случае возникновения вопросов на месте (в реальном времени, в полевых условиях и т.п.) касательно мер снижения воздействия или мониторинга, на которые требуется предоставить безотлагательный ответ;

- Разработать и следовать четкому, структурированному плану осуществления связи и реагирования на случаи столкновений морских млекопитающих с судами или выброса животных на берег. Несмотря на то, что такие происшествия могут быть редкостью или случайным совпадением, желательно разработать план совместно с местными органами власти, содержащий инструкции по реагированию и последующему разбирательству, в случае, если такие события произойдут во время геофизических работ.

Стратегии эффективного планирования в целях управления экологическим риском, связанным с геофизическими и иными исследованиями, направленными на получение графических изображений 
- Специальные меры, применяемые в ходе работ:

- Персонал, отвечающий за меры по снижению воздействия, должен быть достаточно подготовленным, компетентным и не сочетающим выполнение мер с другими обязанностями;

- Персоналу, отвечающему за меры по снижению воздействия, необходимо выделять достаточно времени для отдыха между периодами наблюдений, чтобы персонал мог эффективно выполнять свои обязанности;

- При необходимости реализации мер по снижению воздействия, глава центра управления работами четко и оперативно отдает персоналу распоряжения о выполнении конкретных мер;

- Работы не возобновляются без распоряжения главного координатора, действующего на основе утвержденных протоколов;

- $\quad$ В ходе работ главный координатор обеспечивает, чтобы отчеты о наблюдениях, связанных с мерами по снижению воздействия, должным образом оформлялись, хранились и дублировались, чтобы по итогам работ было возможно составить комплексный отчет.

\section{С. Осуществление протоколов мониторинга, включая проверку и хранение данных}

Методы мониторинга могут включать применение широкого спектра систем дистанционного сбора данных как в реальном времени, так и с использованием записывающих устройств (в соответствии с указаниями в описании Этапа № 2.В). Вне зависимости от источника данных, информация должна проверяться на предмет качества и затем сохраняться. Некоторые методы сбора данных выполняются в рамках снижения воздействия в ходе выполнения работ, а также мониторинга на предмет наличия или отсутствия животных и их возможных реакций. Целью других систем является сбор данных в ходе работ для проведения оценки и документирования результатов выполняемых работ, а также данных об окружающей среде, включая животных, в течение пассивных и активных периодов общих геофизических работ. Протоколы мониторинга включают данные, получаемые на основе методов мониторинга как в реальном времени, так и с использованием записывающих устройств, что требует заблаговременной подготовки, реализации с последующей оценкой, а также интеграции и отчетности после окончания геофизических работ. Данные по мониторингу необходимы для оценки снижения воздействия (Этапы №№ 4.А и 4.Б), анализа и опубликования результатов (Этап № 4.В) и разработки мер по снижению воздействия для будущих работ (Этап № 4.Д).

\section{Заблаговременное планирование мониторинга включает:}

- систематическую проверку и оценку всего оборудования и программного обеспечения мониторинга, включая тестирование с применением систем энергоснабжения на месте, результаты которого могут быть менее точными и достоверными по сравнению с условиями тестирования на стенде, где системы проходили тестирование до начала проведения работ;

- д достаточное количество резервных средств и вспомогательных компьютерных систем на случай отказов оборудования;

- обучение и тестирование систем и средств связи в реальном времени для передачи отчетов о результатах главе центра управления геофизическими работами; и

- $\quad$ наличие хранилища данных и резервных систем для передачи данных в реальном времени и проверка работы систем хранения данных.

\section{Проведение мониторинга включает:}

- систематическую отчетность о результатах мониторинга и проводимых работах, включая результаты мониторинга, которые приводят к применению мер по снижению воздействия;

- с систематическая оценка качества работы систем хранения данных, например акустических записывающих устройств типа, или записей о случаях визуального обнаружения животных;

Стратегии эффективного планирования в целях управления экологическим риском, связанным с геофизическими и иными исследованиями, направленными на получение графических изображений 
- оценка условий шумового воздействия по сравнению с ожидаемыми или оцененными ситуациями (оценка модели на месте) - необходимо подтверждение выполненного до начала работ моделирования условий шумового воздействия; и

- систематическая оценка протоколов записи и хранения данных.

\section{Отчетность по завершению работ и анализ результатов мониторинга включает:}

- «краткие» отчеты с обзором метаданных мониторинга и эффективности проведенных работ к моменту завершения геофизических - глава центра управления должен их проанализировать, перед тем как команда покинет место проведения работы;

- наличие на нескольких объектах резервных хранилищ всех данных мониторинга;

- оценка качества работы каждой команды (поведение, акустика и т.п.) в соответствии с указанными протоколами;

- отчет после завершения геофизических работ с обзором эффективности выполнения программы, оценки эффективности мониторинга и подробной отчетности о результатах мониторинга, включая наблюдения (и их отсутствие), а также данные о трудозатратах (Брокер и др., 2015 г.). Во многих странах данные элементы оцениваются и проверяются компетентными надзорными органами. Степень раскрытия содержания такой оценки указывает на уровень доверия заинтересованных сторон к вышеупомянутому процессу; рекомендуется опубликовать данную оценку. 


\title{
Передовая практика №3:
}

\section{Интеграция мониторинга и мер по снижению воздействия геофизических работ в районе нагула вида, находящегося под угрозой исчезновения - компания «Сахалин Энерджи» (Sakhalin Energy Investment Company)}

\begin{abstract}
В 2010 г. компанией «Сахалин Энерджи» (SEIC) была проведена 4-мерная геофизическая съемка рядом с местами нагула охотско-корейской (западнотихоокеанской) популяции серых китов, Eschrichtius robustus, у восточного побережья о. Сахалин в России. Стремясь минимизировать беспокоящеевоздействиена нагул китов иулучшить понимание потенциальных воздействий геофизических работ на серых китов, «Сахалин Энерджи» разработала и осуществила комплексный план мониторинга и снижения воздействия (ПМСВ). (При рассмотрении данной ситуации кратко описываются некоторые элементы этого ПМСВ; более подробная информация содержится в прошедших коллегиальное рецензирование научных статьях, написанных на основе планирования, сбора и анализа данных, связанных с выполнением ПМСВ. Эти статьи были опубликованы в издании «Еndangered Species Research» в специальном выпуске, озаглавленном «Геофизические работы и западнотихоокеанские серые киты».)
\end{abstract}

Как правило, в планах по снижению воздействия, в основном, предусматривается наличие наблюдателей, работающих на бортугеофизических судов, для мониторинга присутствия морскихмлекопитающихвзапретной зоне, с целью предотращения физических травм у животных в случае столкновения с судами. По причине охраняемого статуса западнотихоокеанских серых китов были реализованы дополнительные защитные меры. Для китов, находящихся в пределах своего нагульного ареала у побережья о. Сахалин, была установлена защитная зона на основе порога акустического беспокоящего воздействия на поведение, равного 156 дБ на мПа $2^{2}$ на импульс, который был определен с помощью исходных данных, собранных в течение нескольких предшествующих лет. Акустические регистраторы, собирающие и передающие данные в реальном времени, были установлены на границе нагульного ареала. В их отношении проводился мониторинг для верификации моделей распространения звука, задействованных заранее, а также с целью избежать наличия недопустимых уровней воздействия в данном критическом районе. Присутствие и активность китов, в особенности впроделах критического прибрежного нагульного ареала, наблюдались и фиксировались береговыми и судовыми группами наблюдателей. Хотя многие геофизические работы проводятся далеко от берега, в некоторыхслучаях, таких как данные геофизические работы СэИК, можно использовать береговые станции для осуществления мониторинга и мер по снижению воздействия. Группы на береговых станциях регистрировали данные о поведении и местонахождениях китов. Эти данные были проанализированы, чтобы выявить, соответственно, поведенческие реакции и изменения в распределении, связанные с геофизическими работами. Судовые группы обеспечивали соблюдение запретной зоны вокруг геофизического судна во избежание получения китами травм и вели мониторинг поведенческих реакций китов вблизи судна.

В период выполнения ПМСВ «Сахалин Энерджи» 2010 года был одним из самых масштабных планов, когдалибо осуществлявшихся в полевых условиях в ходе геофизических работ. Благодаря реализации данного плана удалось добиться как минимум трех важнейших результатов в отношении мониторинга и снижения воздействия в ходе работ, связанных с получением графических изображений о компонентах окружающей среды: во-первых, планирование и предварительная проработка были проведены в значительном

Стратегии эффективного планирования в целях управления экологическим риском, связанным с геофизическими и иными исследованиями, направленными на получение графических изображений 
объеме с использованием исходных данных и разработкой инновационных стратегий для максимального снижения уровня шума, которому может быть подвержена данная популяция, которая находится под угрозой исчезновения. Во-вторых, план был тщательно выполнен и были получены полезные уроки и опыт, которые были учтены в рамках третьего результата, связанного с последующими мероприятиями и распространением информации. Осуществленный при поддержке компании и ее подрядчиков анализ данных и подготовка полученной информации к публикациям являются примером, которому рекомендуется следовать и другим хозяйствующим субъектам. Геофизические работы дали возможность извлечь ценные уроки, касающиеся как разработки и выполнения ПМСВ, так и собранных данных о поведения китов во время геофизических работ. 


\section{Обоснование}

Помимо обеспечения прозрачности, требуемой для подготовки ОВОС до начала работ по освоению месторождения, также необходимо предоставить всем заинтересованным сторонам доступ к результатам программы мониторинга и снижения воздействия, что даст им четкое представление о проделанной работе, оценить, как были решены вопросы, вызывавшие у них озабоченность, а также определить, был ли, по их мнению, обеспечен надлежащий баланс между защитой окружающей среды и эксплуатацией ресурсов. Заинтересованные стороны ожидают гарантий в отношении должного бережливого обращения сприродными ресурсами, а также получения достоверной и полноценной информации о воздействии на окружающую среду работ по освоению энергоресурсов на шельфе. Как упоминалось ранее, учет ответственными операторами преимуществ и недостатков осуществленной в прошлом деятельности идет на пользу бизнесу, и, таким образом, они могут снизить риск нанесения ущерба своей репутации. Следовательно, по завершении геофизических работ логично провести повторную оценку как потенциальных эффектов сейсморазведки, так и эффективности мер снижения воздействия и мониторинга. Такую оценку стоит проводить как на краткосрочной, так и долгосрочной основе, включая способ автоматического учета новой информации и усвоенных уроков для дальнейшего планирования и осуществления мероприятий, в особенности, для более масштабных геофизических операций и планов по освоению месторождений.

По окончании геофизических работ необходимо провести оценку и разбор проведения работ, желательно, с участием ключевого полевого персонала. Затем необходимо продолжить оценку на протяжении этапа анализа данных и составления отчета для достижения двух целей: (1) представление тщательной оценки эффективности выполенения плана мониторинга и снижения воздействия, включая анализ данных и подготовку отчетов и статей для последующего рецензирования и опубликования (в отношении некоторых, но не всех без исключения геофизических работ), и (2) выявление полезных уроков для их учета в последующих программах по мониторингу и снижению воздействия. Обе этих цели зависят от одного критического элемента, а именно, качества сбора данных в ходе программы по мониторингу ОУВ, а также мониторинга проведения самих геофизических работ. Данная оценка вполне может выполняться в виде составления традиционных отчетов по итогам геофизических работ, а также анализа данных в рамках официальных научных исследований и публикаций (см. Передовая практика №4).

Важно, чтобы результаты и анализ данных по мониторингу и мерам по снижению воздействия находились в открытом доступе и в максимально полном виде. Своевременное распространение информации может осуществляться различными способами, например в базах данных в интернете, в отчетах для надзорных органов и (или) рецензируемыхпубликациях. Таким образом, полученные данные и информация помогут лучше изучить вопросы, связанные с рассматриваемыми видами в контексте геофизических или иных подобных исследований. Для достижения максимального эффекта необходимо четко сформулировать и распространить конкретные полезные уроки и рекомендации для последующих геофизических работ, включая оценку мер по снижению воздействия. Может показаться, что последняя ремаркапротиворечит отраслевым стандартам, когда информация часто считается собственностью конкретной компании. Тем не менее, ответственные операторы понимают, что окружающая среда является общим достоянием и что любой фактор, который может помочь операторам снизить уровень их экологических рисков, способен улучшить всемирную репутацию целой отрасли. В то же время отклонение одного оператора от передовой практики может негативно отразиться на репутации остальных компаний, которые ее соблюдают.

Стратегии эффективного планирования в целях управления экологическим риском, связанным с геофизическими и иными исследованиями, направленными на получение графических изображений 


\section{Элементы передовой практики}

\section{А. Отчетность об эффективности программы по снижению воздействия}

Необходимо подготовить и представить заинтересованным сторонам предварительный отчет как можно скорее после завершения программы по мониторингу и снижению воздействия. Такой отчет дает возможность представить общий обзор геофизических работ, объема трудозатрат, эффективности реализации мер по снижению воздействия, любых значимых событий (например остановки работ на основании протоколов по снижению воздействия), исходному анализу данных, а также краткосрочных и долгосрочных планов по проведению аналитических работ. Некоторые компоненты предварительного отчета также можно использовать для информационной работы с общественностью (веб-сайт компании, пресс-релизы и т.п.).

\section{Предварительный отчет может включать следующие элементы:}

1. Краткий обзор осуществленных мер снижения воздействия - Были ли задействованы меры по снижению воздействия? Были ли случаи обнаружения ОУВ? Если да, то были ли причины применения мер по снижению воздействия обоснованными? Здесь должно учитываться мнение экспертов по поводу возможности применения чересчур предосторожного подхода, послуживших причиной для слишком частого применения мер по снижению воздействия, и, как следствие, приведшего к необоснованному увеличению продолжительности геофизических работ;

2. Краткий обзор акустического воздействия-усилия в реальном времени исиспользованиемзаписывающих устройств, зафиксированные уровни и способы соблюдения пороговых значений;

3. Случаи обнаружения - виды, вызывающие наибольший интерес, и другие животные, заслуживающие внимания; наблюдения за животными в нагульных районах или рядом с ними;

4. Поведение - любое отклонение от нормального поведения или отсутствие таких отклонений;

5. Данные - планы по хранению данных, обеспечению и контролю качества и проведению дальнейшего анализа данных.

6. Исходные выводы и рекомендации - вопросы, процедуры или результаты, которые могут представлять непосредственный интерес, к примеру, присутствие ОУВ в контексте других работ в данном районе.

\section{В. Рассмотрение результативности программы мониторинга}

Существует естественное желание как можно скорее завершить один проект и сразу перейти к выполнению следующего. Однако подобная практика может привести к потере ценной информации, которая может способствовать улучшению оценок риска в будущем. Например, выявление степени эффективности конкретной меры по снижению воздействия крайне важно для выработки мер по снижению воздействия в будущем. Особенно важно провести анализ по окончанию работ и представить результаты всем заинтересованным сторонам. Тщательно разработанные и выполненные программы мониторинга могут внести вклад в передовой научный опыт и (или) пересмотр принципов передовой практики для конкретного типа геофизических работ, района их проведения и (или) ОУВ. Если надзорные органы не будут своевременно знакомиться с последними наработками, то они, скорее всего, будут разрабатывать не вполне оптимальные или возможно даже нецелесообразные нормативные требования.

- позволяет определить, достаточно ли адекватны были результаты мониторинга для выявления и устранения любого остаточного риска для ОУВ;

- позволяет рассмотреть и проанализировать данные для проверки на наличие факторов воздействия;

- позволяет провести оценку результатов мониторинга для определения адекватности применения мер по снижению воздействия с точки зрения достижения поставленных целей;

- содержит отчет независимого наблюдателя (в случае его наличия);

Стратегии эффективного планирования в целях управления экологическим риском, связанным с геофизическими и иными исследованиями, направленными на получение графических изображений 
- п позволяет провести оценку оперативных протоколов (система связи, протоколы наблюдений и т.д.) и определить случаи удачного и неудачного соблюдения процедур, включая описание причин;

- $\quad$ позволяет предоставлять рекомендации на предмет разработки в дальнейшем программ мониторинга и снижения воздействия. Такие рекомендации могут быть представлены на различных форумах, включая публикации (рецензируемые и нерецензируемые), а также в рамках презентаций для рассмотрения конкретных примеров на научных конференциях (например, Общества изучения морских млекопитающих (Society for Marine Mammalogy), совещаний с участием отраслевых организаций (МАПНПООС, СИП МАПНГ, МАГП) и конференциях организаций по охране окружающей среды (МСОП и т.д.); и

- позволяетпополнитьцентрализованную базуданныхрелевантной информацией, полученнойв результате работ по мониторингу и снижению воздействия. Логично предположить, что создать и эксплуатировать базы данных столь широкого содержания могут, скорее всего, надзорные органы, а не предприятия отрасли (либо на национальном или на международном уровне на основе сотрудничества с такими организациями, как Международная ассоциация органов охраны окружающей среды при разработке шельфовых нефтегазовых месторождений (International Offshore Petroleum Environmental Regulators, http://www.ioper. org/). Тем не менее, конкретные результаты из отчетов, составленных по окончанию геофизических работ, должны быть внесены в существующие или потенциальные базы данных широкого профиля. Доступ к базам данных должен быть максимально открытым; в случае невозможности обеспечения полной открытости доступа, он должен быть предоставлен сертифицированным специалистам.

\section{С. Своевременный анализ данных и обеспечение доступности результатов}

Общей проблемой в классификации и количественном выражении рисков для морских млекопитающих от шума в ходе геофизических или иных работ по получению графической информации является отсутствие данных или недостаточность передового научного опыта, на основе которых будут оцениваться или прогнозироваться эффекты (в основном, на распределение и поведение животных). Таким образом, усилия по восполнению информационных пробелов должны считаться высшим приоритетом для биологов, занимающихся сохранением видов, профильных специалистов (надзорных органов) и предприятий отрасли. Даже в тех районах, где геофизические работы проводились в течение многих лет (например, северная часть Мексиканского залива, США), отсутствует информация об эффектах и потенциальных рисках для дикой природы. При разработке планов по снижению воздействия, разработки ОВОС и подготовки заявок на получение разрешений, инициаторы проекта должны следовать передовому научному опыту, что обычно означает, в первую очередь, рецензируемую научную литературу. В тех случаях, когда такая литература отсутствует или имеется в неполном объеме, должны быть сформированы значительные стимулы для сбора релевантных данных, проведения соответствующего анализа и публикации результатов в рецензируемой литературе. В таких случаях, средства для анализа данных и публикаций должны закладываться в исходный бюджет проекта и выделяться на начальном этапе планирования. В противном случае мотивация для выполнения таких работ будет минимальной или, в лучшем случае, их выполнение будет необоснованно задержано. В итоге, конечная цель заключается в усвоении полезных уроков и их применении в рамках дальнейших мероприятий по снижению воздействия и мониторингу, чтобы минимизировать воздействия на окружающую среду в результате проведения геофизических работ. Такие уроки необходимо включить в публикуемые материалы о работах по снижению воздействия и мониторингу, причем публикации могут варьироваться от отчетов компаний до рецензируемых статей в научных изданиях.

\section{Меры, способствующие включению результатов в процесс планирования включают:}

1. Обеспечение оперативного выполнения анализа данных и публикации результатов (по крайней мере в некоторых случаях, в рецензируемых научных изданиях, которые находятся в открытом доступе) и информационного обеспечения дальнейших оценок риска, а также мероприятий по снижению воздействия и мониторингу:

Стратегии эффективного планирования в целях управления экологическим риском, связанным с геофизическими и иными исследованиями, направленными на получение графических изображений 
- Финансирование в достаточном объеме для проведения анализа данных и публикации результатов должно быть заложено в бюджет в самом начале процесса;

- Полезно предусмотреть наличие системы субординации по управлению всеми этапами данного процесса, т.е. с самого начала следует определить обязанности персонала, который будет отвечать за сбор данных, проведение анализа и публикацию результатов. Это не означает, что на протяжении всего процесса (учитывая его продолжительность) за определенный вопрос должно отвечать одно и то же лицо; вместо этого, необходимо обеспечить наличие системы передачи информации, а также внедрить соответствующий процесс и обеспечить его соблюдение;

- Применение методов анализа, указанных в Этапе №2 (см. список литературы в Приложении).

- Включение дополнительных аналитических работ по требованию надзорных органов; они во многих случаях могут быть включены в состав других текущих работ по анализу данных.

2. Выявление и устранение пробелов в данных для будущей деятельности и (или) иных видов работ по изучению природных ресурсов; применение передового научного опыта выгодно для всех заинтересованных сторон, поскольку оно снижает неопределенность и, таким образом, повышает результативность. 


\section{Передовая практика №4:}

\section{«Вудсайд Энерджи Лимитед» (Woodside Energy Ltd): Эффекты 3х-мерных морских геофизических работ «Максима» на популяции рыб в лагуне рифа Саут Скотт, Западная Австралия 1}

Были проведены две серии исследований с применением приманочных подводных станций для видеозаписи BRUVS(тм) на площади, составляющей примерно 362 кв. км. в лагуне рифа Саут Скотт в Западной Австралии, с целью обнаружениявоздействий отсборагеофизическихданныхв 2007году(3х-мерныеморскиегеофизические работы «Максима»), осуществленных компанией «Вудсайд Энерджи Лимитед». Дополнительные исследования «Максима» (MPSS) проводились на 20 участках до и после осуществления 3х-мерных морских геофизических работ «Максима». Ввиду большого объема работ в рамках 3х-мерных морских геофизических работ «Максима» и высокой вероятности воздействия на все районы рифа Саут Скотт, найти подходящие контрольные участки не представлялось возможным. Все участки находились в районе, охватываемом Зх-мерными морскими геофизическими работами «Максима», причем данныеучастки были неравномерно распределены между тремя экорайонами, которые были определены как относительно однородные в отношении местообитания рыб на основе результатов предшествующих бентосных исследований. Данные экорайоны, в которых доминируют кораллы, были классифицированы следующим образом: Глубоководный листовидный коралл, Глубоководное сообщество кораллов и наименьший по площади Глубоководный экорайон с высоким разнообразием видов. На каждом участке исследования проводились по четыре раза, дважды до и дважды после, проведения 3х-мерных морских геофизических работ «Максима».

Вторая серия исследований («до-после», контрольное на наличие воздействий) (ВАСІ)) была проведена для того, чтобы компенсировать отсутствие контрольных объектов в дополнительных исследованиях «Максима» (MPSS). сразу после фазы сбора исходных данных был проведен небольшой геофизический тест, который, благодаря своему ограниченному масштабу, позволил сравнить четыре участка, находившихся непосредственно на пути трансекты геофизической съемки, с четырьмя удаленными участками, которые использовались в качестве контрольных. Сразу после проведения геофизических работ на подвергшихся воздействию участках и на контрольных участках была проведена повторная выборка и выполнено небольшое исследование типа ВАСІ. Преимуществом этих исследований, проведенных до начала общего этапа осуществления геофизических работ, служило то, что в них в качестве контрольныхучастков использовались еще не затронутые воздействием районы лагуны. На каждом участке было установлено по четыре дублирующих приманочных подводных видеозаписывающих станции BRUVS (тм) с целью возврата по крайней мере трех успешно отработавших станций в случае неудачной установки по причине опрокидывания оборудования ввиду неровностей рельефа морского дна или сильных течений.

\footnotetext{
1 Australian Institute of Marine Science (AIMS). 2016, The effects on fish communities of Maxima 3D Marine Seismic Surveys at South Scott Reef lagoon, Western Australia: Baited Remote Underwater Video Stations (BRUVS (TM)) Surveys, http://data.aims.gov.au/metadataviewer/faces/view. xhtml?uuid=05966112-387a-4bdb-b27b-882ac1c2fe72
}

Стратегии эффективного планирования в целях управления экологическим риском, связанным с геофизическими и иными исследованиями, направленными на получение графических изображений 


\section{ВЫВВОДЫ}

роцессы и методы, описанные в настоящем документе, предоставляют структурированную основу для ответственного планирования, выполнения и оценки геофизических работ или иных исследований, направленных на получение графических изображений различных компонетов окружающей среды. Начиная с подготовки, проведения и оценки работ и заканчивая выявлением полезных уроков, описанный процесс направлен на реализацию на оперативном уровне элементов, показанных на рисунках 1 и 2, включая полезные уроки на примере рассмотрения конкретных ситуаций с проведением подобных работ в разных странах мира, а также в свете различных существующих нормативно-правовых требований в отношении оценки воздействия, мониторинга и снижения воздействия (Приложение). Общая цель заключается в том, чтобы предоставить менеджерам, ответственным за проведение геофизических работ, отраслевым операторам и надзорным органам методическое руководство, которое поможет им ответственно проводить геофизические работы и иные исследования, направленные на получение графических изображений, и управлять такими работами..

Сцелью обеспечения применимости предлагаемого поэтапного процесса в различных районах и программах, а также ввиду значительного разнообразия типов местообитаний, в которых осуществляются геофизические исследования, представлена подробная информация для обеспечения практического планирования без чрезмерной регламентации в отношении применения точных критериев оценки воздействия или выполнения конкретных мер по снижению воздействия и мониторингу. Тем не менее, настоятельно рекомендуется соблюдать минимальные стандарты мониторинга и снижения воздействия (например, Стандарты деятельности МФК) с целью следования передовым практикам в области охраны окружающей среды. В отношении видов, находящихся под угрозой или на грани исчезновения, в случае выявления относительно высокой степени общего риска в ходе предварительной оценки на основе релевантных контекстуальных переменных (например присутствие вымирающих или особо уязвимых видов), следует применять подходы, предусматривающие более высокую степень защиты, или иные предосторожные подходы, например, комплексное применение различных элементов, описанных в настоящем руководстве. Компаниям следует идентифицировать и внедрять единые меры по охране окружающей среды, более строгие, чем минимальные стандарты, соблюдение которые требует законодательство конкретной страны, поскольку это позволит улучшить последовательность и результативность полевых работ и продемонстрировать, что компании руководствуются принципами передовой практики в области охраны окружающей среды. В заключение необходимо отметить, что операторам геофизических работ рекомендуется соблюдать принципы открытости информации во взаимодействии с заинтересованными сторонами на всех этапах, описанных в настоящем руководстве.

Стратегии эффективного планирования в целях управления экологическим риском, связанным с геофизическими и иными исследованиями, направленными на получение графических изображений 


\section{Библиография}

\section{Этап №1}

Caldwell, L.K. (1988) Environmental Impact Analysis (EIA): Origins, Evolution, and Future Directions, Impact Assessment, 6:3-4, 75-83, DOl: 10.1080/07349165.1988.9725648

Harrison, J., Ferguson, M., Gedamke, J., Hatch, L., Southall, B., \& Van Parijs, S. (2016). National Oceanic and Atmospheric Administration's Cetacean and Sound Mapping Effort: Continuing Forward with an Integrated Ocean Noise Strategy. In The Effects of Noise on Aquatic Life II (pp. 409-416). Springer New York. http://dx.doi.org/10.1007/978-1-4939-2981$8 \_48$

Fleishman, E., Costa, D. P., Harwood, J., Kraus, S., Moretti, D., New, L. F., ... \& Wells, R. S. (2016). Monitoring populationlevel responses of marine mammals to human activities. Marine Mammal Science.

DOI: $10.1111 / \mathrm{mms} .12310$

Nowacek, D.P., Clark, C.W., Mann, D., Miller, P.J.O., Rosenbaum H.C., Golden, J.S., Jasny, M., Kraska, J., and Southall, B.L. (2015). Marine Seismic Surveys and Ocean Noise: Time for coordinated and prudent planning. Frontiers in Ecology and the Environment 13, 378-386. DOl:10.1890/130286.

Nowacek, D.P., Clark, C.W., Donovan, G., Gailey, G., Golden, J., Jasny, M., Mann, D.A., Miller, P.J., Racca, R., Reeves, R.R., Rosenbaum, H., Southall, B., Vedenev, A., and Weller, D.W. (2015). Marine seismic surveys and ocean noise: mitigation, monitoring and a plan for international management. 21st Biennial Conference on the Biology of Marine Mammals, San Francisco, CA, USA, 13-18 December.

Nowacek, D.P. Bröeker, K., Donovan, G., Gailey, G., Racca, R., Reeves, R.R., Vedenev, A.I., Weller, D.W., and Southall, B.L. (2013). Responsible Practices for Minimizing and Monitoring Environmental Impacts of Marine Seismic Surveys with an Emphasis on Marine Mammals. Aquatic Mammals 39, 356-377. http://dx.doi.org/10.1578/AM.39.4.2013.356

Rutenko, A. N., Borisov, S. V., Gritsenko, A. V., \& Jenkerson, M. R. (2007). Calibrating and monitoring the western gray whale mitigation zone and estimating acoustic transmission during a 3D seismic survey, Sakhalin Island, Russia. Environmental monitoring and assessment, 134(1-3), 21-44.

http://dx.doi.org/10.1007/s10661-007-9814-z

\section{Этап №2}

Ellison, W. T., Racca, R., Clark, C. W., Streever, B., Frankel, A. S., Fleishman, E., Angliss, R., Berger, J., Ketten, D., Guerra, M., Leu, M., McKenna, M., Sformo, T., Southall, B., Suydam, R., and Thomas, L. (2016). Modeling the aggregated exposure and responses of bowhead whales Balaena mysticetus to multiple sources of anthropogenic underwater sound. Endangered Species Research, 30, 95-108. http://dx.doi.org/10.3354/esr00727

Ellison, W.T., Clark, C.W., Mann, D.A., Southall, B., and Tollit, D.J. (2015). A risk assessment framework to assess the biological significance of noise exposure on marine mammals. 21st Biennial Conference on the Biology of Marine Mammals, San Francisco, CA, USA, 13-18 December.

Стратегии эффективного планирования в целях управления экологическим риском, связанным с геофизическими и иными исследованиями, направленными на получение графических изображений 
Ellison, W. T., Southall, B. L., Clark, C. W., \& Frankel, A. S. (2012). A new context-based approach to assess marine mammal behavioral responses to anthropogenic sounds. Conservation Biology, 26(1), 21-28. http://dx.doi.org/10.1111/j.15231739.2011.01803.x

Fleishman, E., Streever, B., Angliss, R., Clark, C. W., Ellison, W. T., Frankel, A., \& Simmons, S. (2016). Current Status of Development of Methods to Assess Effects of Cumulative or Aggregated Underwater Sounds on Marine Mammals. In The Effects of Noise on Aquatic Life II (pp. 303-311). Springer New York. http://dx.doi.org/10.1007/978-1-4939-29818_36

Frankel, A. S., Ellison, W. T., Vigness-Raposa, K. J., Giard, J. L., and Southall, B. L. (2016). Stochastic Modeling of Behavioral Response to Anthropogenic Sounds. In The Effects of Noise on Aquatic Life II (pp. 321-329). Springer New York. http:// dx.doi.org/10.1007/978-1-4939-2981-8_38

Joint Nature Conservation Committee (INCC). (2010). JNCC guidelines for minimising the risk of injury and disturbance to marine mammals from seismic surveys. Aberdeen, Scotland: JNCC. 16 pp.

Nowacek, D. P., Vedenev, A., Southall, B. L., \& Racca, R. (2012). Development and implementation of criteria for exposure of western gray whales to oil and gas industry noise. Advances in Experimental Medicine and Biology, 730, 523-528. http://dx.doi.org/10.1007/978-1-4419-7311-5_119

Southall, B. L., Bowles, A. E., Ellison, W. T., Finneran, J. J., Gentry, R. L., Greene, C. R., Jr., Tyack, P. L. (2007). Marine mammal noise exposure criteria: Initial scientific recommendations. Aquatic Mammals, 33(4), 411-521. http://dx.doi. org/10.1578/AM.33.4.2007.411

\section{Этап №3}

Blackwell, S. B., Nations, C. S., McDonald, T. L., Greene, C. R., Thode, A. M., Guerra, M., \& Michael Macrander, A. (2013). Effects of airgun sounds on bowhead whale calling rates in the Alaskan Beaufort Sea. Marine Mammal Science, 29(4), E342-E365. http://dx.doi.org/10.1111/mms.12001

Bröker, K., Gailey, G., Muir, J. E., \& Racca, R. (2015). Monitoring and impact mitigation during a 4D seismic survey near a population of gray whales off Sakhalin Island, Russia. Endang Species Res, 28, 187-208. http://dx.doi.org/10.3354/ esr00670

Thode, A. M., Kim, K. H., Blackwell, S. B., Greene Jr, C. R., Nations, C. S., McDonald, T. L., \& Macrander, A. M. (2012). Automated detection and localization of bowhead whale sounds in the presence of seismic airgun surveys. The Journal of the Acoustical Society of America, 131(5), 3726-3747. http://dx.doi.org/10.1121/1.3699247

\section{Этап №4}

Blackwell, S. B., Nations, C. S., McDonald, T. L., Thode, A., Kim, K. H., Greene Jr, C. R., \& Macrander, A. M. (2010). Effects of seismic exploration activities on bowhead whale call distribution in the Alaskan Beaufort Sea. The Journal of the Acoustical Society of America, 127(3), 1756-1756.

http://dx.doi.org/10.1121/1.3383702

Blackwell, S. B., Nations, C. S., McDonald, T. L., Thode, A. M., Mathias, D., Kim, K. H., ... \& Macrander, A. M. (2015). Effects of airgun sounds on bowhead whale calling rates: evidence for two behavioral thresholds. PloS one, 10(6), e0125720.

Стратегии эффективного планирования в целях управления экологическим риском, связанным с геофизическими и иными исследованиями, направленными на получение графических изображений 
http://dx.doi.org/10.1371/journal.pone.0125720Cerchio, S., Strindberg, S., Collins, T., Bennett, C., \& Rosenbaum, H. (2014). Seismic surveys negatively affect humpback whale singing activity off northern Angola. PloS one, 9(3), e86464. http://dx.doi.org/10.1371/journal.pone.0086464

Gailey, G., Sychenko, O., McDonald, T., Racca, R., Rutenko, A., \& Bröker, K. Behavioural responses of western gray whales to a 4-D seismic survey off northeastern Sakhalin Island, Russia. Endang Species Res, doi, 10.

Gailey, G., Würsig, B., \& McDonald, T. L. (2007). Abundance, behavior, and movement patterns of western gray whales in relation to a 3-D seismic survey, Northeast Sakhalin Island, Russia. Environmental Monitoring and Assessment, 134, 75-91. http://dx.doi.org/10.1007/s10661-007-9812-1

Jefferson, T. A., Hung, S. K., \& Würsig, B. (2009). Protecting small cetaceans from coastal development: Impact assessment and mitigation experience in Hong Kong. Marine Policy, 33(2), 305-311. http://dx.doi.org/10.1016/j.marpol.2008.07.011

Muir, J. E., Ainsworth, L., Racca, R., Bychkov, Y., Gailey, G., Vladimirov, V., ... \& Bröker, K. (2016). Gray whale densities during a seismic survey off Sakhalin Island, Russia. Endangered Species Research, 29(3), 211-227. http://dx.doi.org/10.3354/ esr00709

Muir, J. E., Ainsworth, L., Joy, R., Racca, R., Bychkov, Y., Gailey, G., .. \& Bröker, K. (2015). Distance from shore as an indicator of disturbance of gray whales during a seismic survey off Sakhalin Island, Russia. Endangered Species Research, 29, 161-178. http://dx.doi.org/10.3354/esr00701

Jefferson, T. A., Hung, S. K., \&Würsig, B. (2009). Protecting small cetaceans from coastal development: Impact assessment and mitigation experience in Hong Kong. Marine Policy, 33(2), 305-311. http://dx.doi.org/10.1016/j.marpol.2008.07.011 


\section{Приложение}

Данное приложение является инструментом, действующим в режиме онлайн и предназначенным для отраслевых компаний, надзорных органов и исследователей, чтобы они могли пользоваться информацией, касающейся каждого из четырех этапов планирования в рамках Эффективной стратегии планирования геофизических работ и иных исследований, направленных на получение графических изображений окружающей среды. База данных в режиме онлайн содержит опубликованные реферируемые научные публикации, национальные и международные нормативные документы, правила и инструкции, технические отчеты и обзоры. Каждый документ в базе данных содержит несколько важных элементов информации, включая: страну происхождения/организацию, применение документа (обязательное или рекомендуемое), географический охват, применимость в предлагаемых рамках и факт наличия или отсутствия в документе релевантной информации в отношении мониторинга, снижения воздействия, сбора исходных данных, методов анализа, критериев воздействия, кумулятивного воздействия или указанных ключевых видов. Многие методические рекомендации, указанные в данном Приложении, применимы в масштабах одного государства, т.е. впределахисключительной экономическойзоны одной страны или впределахграниц ее континентального шельфа. Однако в случаях, связанных, например, с деятельностью Арктического совета, в контексте данного документа рассматривается весь бассейн Северного ледовитого океана. Иные методические документы, например, действующие в Западной Австралии, содержат специфические для региона рекомендации по техническим требованиям в отношении проведения геофизических работ.

Ресурсы, перечисленные в данном Приложении, доступны в базе данных в режиме онлайн с соответствующими ключевыми словами и ссылками на документы в формате pdf в случае их наличия.

http://www.iucn.org/western-gray-whale-advisory-panel/panel/seismic-surveys-monitoring-and-mitigation 






\section{IUCN}

МЕЖДУНАРОДНЫЙ СОЮЗ ОХРАНЫ ПРИРОДЫ

ШТАБ-КВАРТИРА

РЮ МОВЕРНИ, Д.28

1196, Г. ГЛАНД ШВЕЙЦАРИЯ

ТЕЛ.: +41 229990000

ФAKC: +41 229990002

WWW.IUCN.ORG

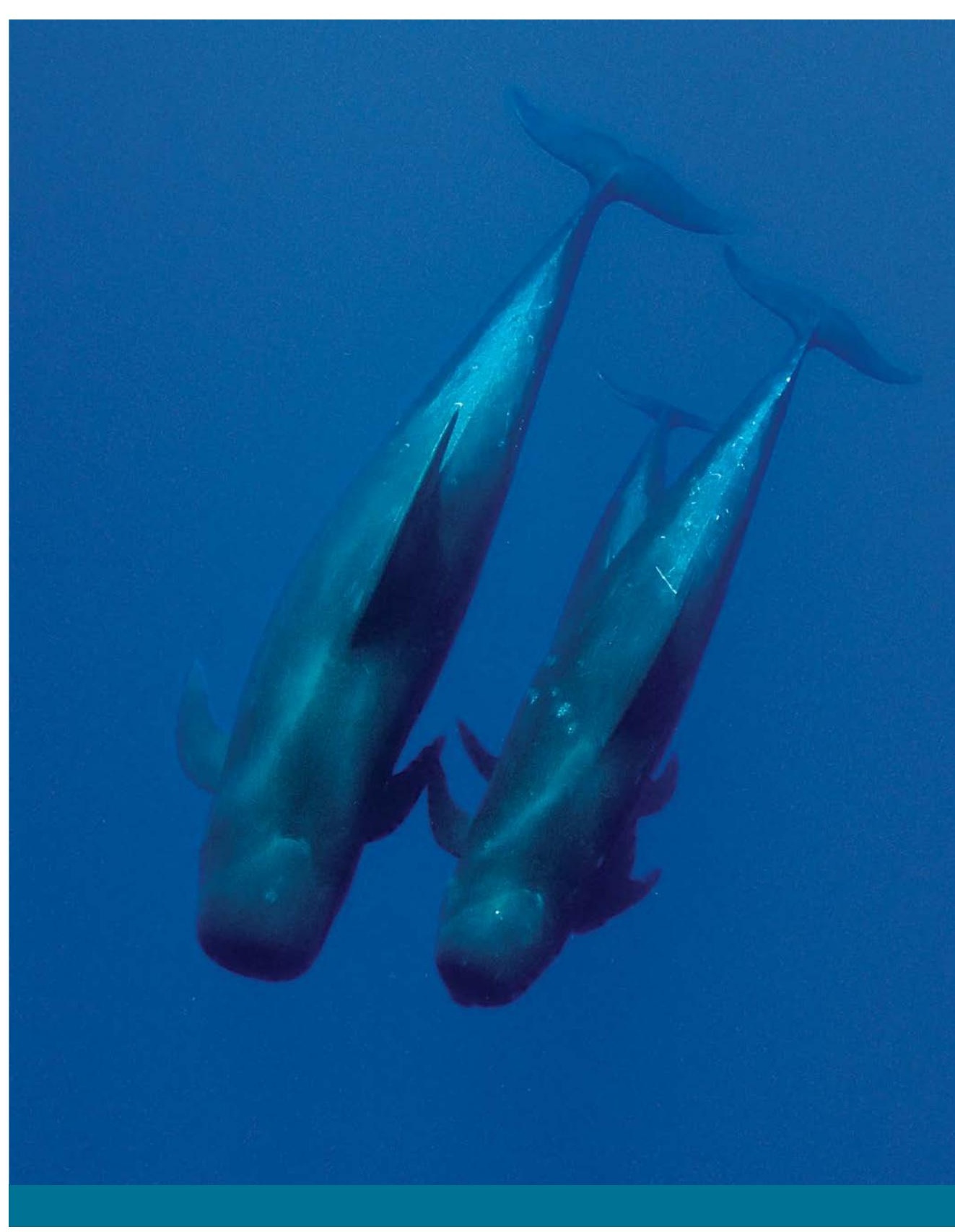

